UNIVERSIDADE DE SÃo PAULO

ESCOLA DE ENFERMAGEM

O acesso das mulheres a serviços comunitários de saúde mental em álcool e outras drogas: uma revisão de escopo

Thais Yshida Cestari Lockley

São Paulo 
Thais Yshida Cestari Lockley

\title{
O acesso das mulheres a serviços comunitários de saúde mental em álcool e outras drogas: uma revisão de escopo
}

\author{
Versão corrigida da dissertação apresentada ao \\ Programa de Pós Graduação da Escola de \\ Enfermagem da Universidade de São Paulo para a \\ obtenção do título de Mestre em Ciências. \\ Área de Concentração: Cuidado em Saúde \\ Orientadora: Prof. ${ }^{\text {a }}$ Dr. ${ }^{\underline{a}}$ Márcia Aparecida Ferreira \\ de Oliveira
}

\section{VERSÃO CORRIGIDA}

A versão original encontra-se disponível na Biblioteca da Escola de Enfermagem da Universidade de São Paulo e na Biblioteca Digital de Teses e Dissertações da Universidade de São Paulo.

São Paulo 
AUTORIZO A REPRODUÇÃO E DIVULGAÇÃO TOTAL OU PARCIAL DESTE TRABALHO, POR QUALQUER MEIO CONVENCIONAL OU ELETRÔNICO, PARA FINS DE ESTUDO E PESQUISA, DESDE QUE CITADA A FONTE.

Assinatura:

Data:

Catalogação na Publicação (CIP)

Biblioteca "Wanda de Aguiar Horta"

Escola de Enfermagem da Universidade de São Paulo

Lockley, Thais Yshida Cestari

O acesso das mulheres a serviços comunitários de saúde mental em álcool e outras drogas: uma revisão / Thais Yshida Cestari Lockley. São Paulo, 2018.

$65 \mathrm{p}$.

Dissertação (Mestrado) - Escola de Enfermagem da Universidade de São Paulo.

Orientadora: Prof. a Dr. ${ }^{\text {a }}$ Márcia Aparecida Ferreira de Oliveira

Ficha catalográfica elaborada por Fabiana GulinLonghiPalacio (CRB-8: 7257) 
Nome: Thais Yshida Cestari Lockley

Título:O acesso das mulheres a serviços comunitários de saúde mental em álcool e outras drogas: uma revisão de escopo

Dissertação apresentada à Escola de Enfermagem da Universidade de São Paulo para obtenção do título de Mestre em Ciências da Saúde.

Aprovado em

\section{BANCA EXAMINADORA}

Prof. Dr. Instituição:

Julgamento:

Assinatura:

Prof. Dr. Instituição:

Julgamento: Assinatura:

Prof. Dr. Instituição:

Julgamento: Assinatura: 


\section{DEDICATÓRIA}

À minha esposa Anne.

Aos meus pais, Valéria e Marco.

Aos meus amigos.

Aos meus gatos que sempre estiveram estudando junto e aos meus cachorros que não pararam de latir.

Aos membros do Grupo de Estudos em Álcool e outras Drogas- GEAD. 


\section{AGRADECIMENTOS}

Primeiramente gostaria de agradecer meus pais, Valéria e Marco que sempre me ensinaram a importância dos estudos, no qual poderia conquistar meus sonhos. Sempre estiveram comigo e me apoiaram quando eu mais precisava em toda a minha trajetória desde o ingresso á graduação.

À minha esposa Anne que com muita paciência sempre me apoiou e me estimulou a escrever, pesquisar e conquistar meu sonho. Sempre brigou comigo por deixar a escrita para última hora! Também demonstrou muita paciência e companheirismo em todos os momentos que precisei chegar mais tarde em casa e quando não pude ajudar muito pois, estava imersa em escrita.

À minha irmã Beatryz que sempre me questionou em que momento estava da minha dissertação e me lembrava o quanto tinha batalhado.

À minha sogra Maria do Carmo, que me auxiliou muito com as traduções e correções! Além de sempre com bom humor me deixar bilhetinhos" nas traduções!

À Prof ${ }^{a} \mathrm{Dr}^{\mathrm{a}}$ Márcia Aparecida Ferreira de Oliveira, minha orientadora e amiga desde a graduação com as iniciações científicas. Sempre me apoiando e me mostrando caminhos que poderiam ser percorridos em busca de conhecimento e oportunidades.

À Prof ${ }^{a} \mathrm{Dr}^{\mathrm{a}}$ Maria Odete Pereira que esteve comigo em minha primeira iniciação científica, me ensinando o poder das palavras e me ensinando a realizar pesquisa de campo.

À Prof ${ }^{a} \mathrm{Dr} \stackrel{\text { a }}{ }$ Mária do Perpétuo S.S. Nóbrega pelos apontamentos no momento da defesa e pelo carinho, cuidado e aposta em diversos momentos da vida.

Aos integrantes do grupo de pesquisa GEAD, especificamente ao Dr. Ricardo Henrique Soares que esteve comigo em todo o trabalho da dissertação e anteriormente, durante a graduação.

A todos os meus campos de trabalho que me proporcionaram conhecimento, oportunidades e aprendizado.

Por fim, a todos os usuários que me mostraram o valor da vida em meio ao sofrimento. 


\begin{abstract}
Alma Luz
Minha alma tem o peso da luz

Tem o peso da música

Tem o peso da palavra nunca dita,

Prestes quem sabe a ser dita

Tem o peso de uma lembrança

Tem o peso de uma saudade

Tem o peso de um olhar

Pesa como pesa uma ausência

E a lágrima que não chorou

Tem o imaterial peso de uma solidão

No meio de outros
\end{abstract}

\title{
Clarice Lispector
}


LOCKLEY, TYC. O acesso das mulheres a serviços comunitários de saúde mental em álcool e outras drogas: uma revisão de escopo [Dissertação]. São Paulo (SP), Brasil: Escola de Enfermagem, Universidade de São Paulo; 2018. $65 \mathrm{p}$.

\section{RESUMO}

A dependência de substâncias psicoativas cresceu entre as mulheres para 6,9\% em relação ao álcool, 5,1\% para maconha, cocaína aumentou para 1,2\%, estimulantes para $4,5 \%$ e os benzodiazepínicos $6,9 \%$. Mesmo com o aumento da prevalência desse consumo a porcentagem de mulheres que recebeu algum tipo de tratamento especializado caiu de $2,5 \%$, para 1,6\%. Para essa população, o Brasil não possui diretrizes específicas quanto ao acesso ao cuidado em álcool e drogas. O objetivo foi realizar uma revisão de escopo acerca do acesso das mulheres em serviços comunitários de saúde mental em álcool e outras drogas. O estudo apresentado é uma revisão de escopo. O levantamento bibliográfico foi realizado em sete bases de dados - Psyinfo, Cinahal, Scopus, Pubmed, BVS, Embase e Indexpsiperiódicos. Os dados extraídos foram sintetizados de modo narrativo. Buscou-se responder a seguinte indagação: quais são as barreiras que influenciam o acesso das mulheres em serviços comunitários de saúde mental em álcool e outras drogas? O resultado inicial da revisão foi de 601 trabalhos e 12 trabalhos foram inseridos na análise final. O conteúdo foi descrito em três categorias de análise: 1- Construção social do gênero feminino; 2- Estigma social e 3- Determinantes sociais. As mulheres necessitam de ações voltadas para seu cuidado permeadas pelas condições específicas do gênero. Discussões acerca do papel pré-determinado à mulher em nossa sociedade, violência de gênero, função maternal, traumas físicos e psicológicos devem ser defnidos no acolhimento integral proporcionado pelos serviços. Como sugestão, além de estudos que identificam os acessos dessa população a atenção integral à saúde, outros estudos são necessários em relação à avaliação da continuidade do tratamento e inserção das mulheres em tratamentos específicos.

Descritores: Serviços Comunitários de Saúde Mental; Mulher(es); Transtornos Relacionados ao Uso de Substâncias; Enfermagem. 
LOCKLEY, TYC. Women's access to community mental health services in alcohol and other drugs: a scope review [Dissertação]. São Paulo (SP), Brasil: Escola de Enfermagem, Universidade de São Paulo; 2018. 65 p.

\begin{abstract}
The dependence of psychoactive substances increased among women to $6.9 \%$ in relation to alcohol, $5.1 \%$ to marijuana, cocaine increased to $1.2 \%$, stimulants to $4.5 \%$ and benzodiazepines $6.9 \%$. Even with the increase in the prevalence of this consumption, the percentage of women who received some type of specialized treatment dropped from $2.5 \%$ to $1.6 \%$. For this population, Brazil does not have specific guidelines regarding access to alcohol and drug care. The objective was to conduct a review of the scope of women's access to community mental health services in alcohol and other drugs. The study presented is a review of scope. The bibliographic survey was performed in seven databases Psyinfo, Cinahal, Scopus, Pubmed, BVS, Embase and Indexpsiperiódicos. The extracted data were synthesized in a narrative way. We sought to answer the following question: what are the barriers that influence women's access to community mental health services in alcohol and other drugs? The initial result of the review was 601 papers and 12 papers were inserted in the final analysis. The content was described in three categories of analysis: 1- Social construction of the female gender; 2 - Social stigma and 3- Social determinants. Women need actions aimed at their care permeated by the specific conditions of the gender. Discussions about the pre-determined role of women in our society, gender violence, maternal function, physical and psychological trauma should be defined in the full reception provided by the services. As a suggestion, in addition to studies that identify the accesses of this population to the integral health care, other studies are necessary in relation to the evaluation of the continuity of the treatment and insertion of the women in specific treatments.
\end{abstract}

Key words: Community Mental Health Services; Women); Disorders Related to Substance Use; Nursing. 


\section{LISTA DE SIGLAS}

Reforma Psiquiátrica Brasileira: RPB

Sistema Único de Saúde: SUS

Centro de Atenção Psicossocial: CAPS

Programa de Avaliação de Serviços de Saúde: PNASS

Política Nacional de Drogas: PND

Álcool e outras Drogas: AD

Centro de Atenção Psicossocial em Álcool e outras Drogas: CAPS AD

Doenças Sexualmente Transmissíveis/Síndrome da Imunodeficiência Adquirida (acquiredimmunodeficiencysyndrome): DST/AIDS

Álcool e outras Drogas: AD

Organização Mundial da Saúde: OMS

Agência Nacional de Vigilância Sanitária: ANVISA

Rede de Atenção Psicossocial: RAPS

Núcleos de Atenção Psicossocial: NAPS

Centros de Referência em Saúde Mental: CERSAM's

Unidade Básica de Saúde: UBS

Estratégia Saúde da Família: ESF

Projeto Terapêutico Singular: PTS

Prática baseada em evidências: PBE

Instituto Joana Briggs: JBI

Substância psicoativa: SPA 


\section{SUMÁRIO}

1. Introdução 12

1.1. Revisão da Literatura 144

1.1.1. Políticas de Álcool e Outras Drogas 144

1.1.2. Serviços Comunitários de Saúde Mental 177

1.1.3. Mulheres e Álcool e Outras Drogas 211

2. Justificativa do estudo e Objetivos 244

2.1. Justificativa do Estudo 244

2.2. Objetivos 255

2.2.1. Objetivo Geral 255

2.2.2. Objetivo Específico 266

3. Metodologia 266

3.1. Etapas da Revisão de Escopo 288

3.2. Questões Norteadoras 2929

3.3. Critérios de Inclusão 30

3.4. Estratégia de Pesquisa e Palavras Chaves 300

3.5. Seleção dos Estudos 331

3.6. Extração dos Resultados e Apresentação dos Resultados 34

3.7. Referencial Teórico 344

4. Resultados 36

4.1. Categorias de Análise 377

4.1.1. Barreiras de Acesso 39

4.1.2. Barreiras Internas: Construção Social do Gênero Feminino e Estigma Social 41 4.1.3. Barreiras Externas: Determinantes Sociais Erro! Indicador não definido.1

5. Discussão 42

6. Considerações Finais 52

7. Referências 55

8. Apêndices 60

8.1. Formulário de Extração de Dados Apêndice 1 60

8.2. Protocolo da Revisão de Escopo Apêndice 2 61 


\section{Introdução}

A hegemonia do modelo psiquiátrico clássico no tratamento das pessoas com transtornos mentais perdurou no Brasil até meados de 1970, via isolamento dos usuários em hospitais psiquiátricos e manicômios, por tempo indeterminado (1).

As primeiras críticas a respeito desse modelo emergiram na Europa, classificando-o como desumano, iatrogênico e perverso. No Brasil, surgiram em 1950, com o movimento denominado de desinstitucionalização psiquiátrica (2).

O movimento visava a garantia de direitos das pessoas com transtornos mentais e todos os comprometimentos advindos de internações prolongadas, sustentando que a reinserção social não era beneficiada por tais ações ${ }^{(1)}$.

Como marco importante ao processo da Reforma Psiquiátrica Brasileira (RPB) aconteceu a 8를 Conferência Nacional em Saúde, em 1986 na qual se formou uma comissão para cuidar da assistência em saúde mental. Outro apontamento acerca de uma proposta pela comissão foi o atendimento prestado nas emergências psiquiátricas, que deveriam serem realizadas em hospitais gerais ${ }^{(1-2)}$.

O seguimento das ações referentes ao processo da RPB ganhou maior efetividade após a $1^{\text {a }}$ Conferência Nacional de Saúde Mental e o $2^{\circ}$ Congresso Nacional dos Trabalhadores de Saúde Mental, realizados em Bauru (SP), no dia 18 de maio de 1987. Repetidamente propõem-se a criação de serviços substitutivos aos hospitais psiquiátricos e aos manicômios e a diminuição do tempo de hospitalização. A partir dessas propostas, o movimento de reforma ganhou a participação de familiares e de pessoas com transtornos mentais (1).

Em 1989, há o envio ao Congresso Nacional do Projeto de Lei denominado "Paulo Delgado", buscando mudanças na assistência das pessoas com transtornos mentais ${ }^{(1-2)}$.

Em 1990, o marco histórico foi a assinatura da Declaração de Caracas, no qual o governo brasileiro assumia o compromisso de garantir direitos aos usuários com transtornos mentais e organizar os serviços substitutivos aos hospitais psiquiátricos ${ }^{(1-3)}$.

Foi em 1991 e 1992 que a criação de serviços comunitários de saúde mental se intensificou. Nesse período foram aprovadas as Portarias 189/91 e 
224/92 do Ministério da Saúde, garantindo ao Sistema Único de Saúde (SUS) a condição de ofertar assistência humanizada e comunitária em saúde mental Centro de Atenção Psicossocial (CAPS), Lares Abrigados, grupos de orientação e entre outros. Especificamente a Portaria 224/92 oficializou o funcionamento dos serviços substitutivos aos hospitais psiquiátricos - CAPS (1-3).

Passados 12 anos de um longo e árduo percurso frente a modificação da assistência em saúde mental e psiquiátrica, a Lei Federal 10.2016 foi aprovada em 06 de Abril de 2001 ${ }^{(1-4)}$.

Mesmo com a promulgação da legislação que passou a ser conhecida como Lei da Reforma Psiquiátrica, outras Portarias e Legislações foram criadas após 2001 com o intuito de regulamentar o atendimento psiquiátrico comunitário. Podemos citar o Programa "De Volta para Casa", que regulamenta o auxílioreabilitação aos usuários que permaneceram por longos períodos internados em instituições psiquiátricas e a Portaria 336/GM, que define o papel central do CAPS no cuidar em liberdade ${ }^{(1-2)}$.

A RPB segue com as mudanças; continua o processo de diminuição de leitos em hospitais psiquiátricos e a criação de CAPS nas diversas cidades brasileiras. Ressalta-se que em 2004 foi criado o Programa de Avaliação de Serviços de Saúde (PNASS); a fim de auxiliar na avaliação das intervenções que são realizadas e avaliar as propostas de melhorias ${ }^{(1-2)}$.

Por fim, mesmo com as mudanças na estrutura do atendimento, o processo de reforma encontra-se em constante formulação e reformulação, a fim de garantir cidadania e direitos às pessoas que são acometidas por transtornos mentais ${ }^{(2-4)}$.

Uma das práticas de cuidado e abordagem refere-se à atenção integral em álcool e outras drogas. Historicamente o sujeito que faz uso de álcool e outras drogas é vinculado a uma esfera moralista, algo relacionado ao seu caráter.

A dependência de álcool e outras drogas é um fenômeno complexo que deve ser entendido com uma questão de saúde pública. Deve também ser compreendido com transversalidade no âmbito do SUS, discorrendo de particularidades relacionadas ao consumo de álcool e outras drogas e a prática de cuidados da saúde coletiva ${ }^{(1-2)}$. 
A Política de Atenção Integral à Usuários de Álcool e outras Drogas do Ministério da Saúde propõe um novo olhar de cuidado a esses sujeitos (1-2). Apresenta como diretrizes a intersetorialidade, a atenção integral em saúde, a prevenção e promoção e proteção à saúde das pessoas que fazem uso de álcool e outras drogas (politica de álcool e outras drogas).

Pesquisas acerca do consumo de álcool e outras drogas indicam que em um intervalo de quatro anos, a dependência de álcool em mulheres com idade entre 12 e 65 anos, cresceu de 5,7 \% para 6,9\%. O uso de maconha durante a vida subiu de $3,4 \%$ para $5,1 \%$; de cocaína aumentou de $0,9 \%$ para $1,2 \%$ e os estimulantes de $2,2 \%$ para $4,5 \%$. Por fim, de benzodiazepínicos passaram de $4,3 \%$ para $6,9 \%$. Mesmo com o aumento da prevalência no consumo de drogas lícitas e ilícitas, a porcentagem de mulheres que recebeu algum tipo de tratamento especializado, em 2005 caiu de 2,5\%, em 2001 para1,6\% ${ }^{5-8}$.

O Plano Nacional de Políticas para as Mulheres entre 2013-2015 adquire como meta a inserção de mulheres usuárias de substâncias psicoativas (SPA) na rede de serviços de saúde, por medidas tomadas pelo Ministério da Saúde (6). Apesar do avanço com a definição da Política Nacional de Drogas (PNAD) (7) de 2010, o País não se atentou às necessidades de mulheres usuárias de drogas em suas especificidades, não estabelecendo diretrizes quanto à captação e retenção dessa clientela nos espaços de tratamento ${ }^{(5-8)}$.

\subsection{Revisão da Literatura}

\subsubsection{Políticas de Álcool e Outras Drogas}

No Brasil, a garantia de direitos e acesso à saúde dá-se pelas diretrizes do SUS, regida pela Lei 8080/90 e reeditada pela Lei 8142/90. Assim sendo, tem por finalidade a promoção de saúde com qualidade de vida a toda população brasileira ${ }^{(9)}$.

Conforme relatado anteriormente, a Lei 10.2016/2001 corroborou com as diretrizes básicas de acesso e direitos à população que sofre por transtornos mentais e consequentemente às pessoas que fazem uso/uso abusivo de álcool e outras drogas ${ }^{(9-11)}$. 
No Brasil, em 2002, após recomendações realizadas pela III Conferência Nacional em Saúde Mental, o Ministério da Saúde implementa o Programa Nacional de Atenção Comunitária Integrada aos Usuários de Álcool e outras Drogas ${ }^{(9-12) \text {. }}$

A diretriz principal para o tema de álcool e outras drogas foi à publicação pelo Ministério da Saúde, em 2003, da Política do Ministério da Saúde para Atenção Integral a Usuários de Álcool e Outras Drogas. Essa Política está voltada para a especificidade de seu público alvo e se embasa nos princípios do SUS e no Movimento de Reforma Psiquiátrica (9-12).

Com efeito, a política de saúde mental garante ao usuário: ampliação do acesso ao tratamento e compreensão integral do fenômeno; ações de promoção, prevenção, proteção à saúde e educação das pessoas que fazem uso prejudicial de álcool e outras drogas (AD); rede estratégica de serviços extra-hospitalares, articulada com a rede de atenção psicossocial - Centro de Atenção Psicossocial em álcool e outras drogas (CAPS AD). Parte-se da estratégia de cuidado na lógica ampliada da Redução de Danos ${ }^{(9-11)}$.

De acordo com a Organização Mundial da Saúde (OMS), 10\% da população mundial de centros urbanos fazem uso abusivo de álcool e outras drogas, independentemente da faixa etária, raça, sexo e condições financeiras. Historicamente o consumo de álcool e outras drogas é permeado por diversas esferas como criminal, religiosa, educacional, saúde, social e entre outras ${ }^{(9)}$.

Muitas vezes o cuidado ofertado se dirige à exclusão do usuário de seu convívio social, geralmente parte-se do recurso de abstinência total; reforçado pelo conceito de combater a substância utilizada. Tal visão moralista acerca do sujeito que faz o uso de determinada substância prejudica o cuidado inserido na comunidade e promove a fragmentação do acolhimento ofertado (9-10).

Afirma-se que a questão do uso e consumo de álcool e outras drogas trata-se de um grave problema de saúde pública. Logo, as Políticas de atenção frente as estratégias de promoção, prevenção, tratamento e educação deverão ser construídas junto da sociedade civil; a fim de garantir que a abstinência não seja a única meta a ser estabelecida para os usuários (9-12).

A dependência de substâncias psicoativas é um fenômeno complexo, uma vez que influencia as pessoas de diferentes maneiras, em diferentes contextos e com diferentes razões. Por tratar-se de um fenômeno complexo e 
pouco compreendido em muitos casos, a adesão em serviços comunitários de álcool e outras drogas é baixa. Ainda, constantemente é presenciado o aparecimento de novas substâncias psicoativas que se adequam a essas diferentes formas de atingir a população ${ }^{(9-12)}$.

Distinguir o usuário frente a sua singularidade e suas necessidades exige o aprimoramento do profissional relacionando formas de vínculo e atenção diferenciado ${ }^{(9-11)}$.

Por fazer o cuidado em saúde, deve-se assimilar a saúde coletiva e os conceitos da clínica do álcool e outras drogas; lógica da transversalidade do cuidado em saúde. Um grande desafio à prática em saúde, uma vez que garante a construção de novos olhares, saberes e dispositivos de intervenções (9-10).

Partindo da perspectiva que a abstinência das substâncias psicoativas não é a única forma de tratamento do uso, um método um tanto excludente; a estratégia de Redução de Danos propõe co-participação e responsabilização do sujeito frente ao seu tratamento; promovendo a criação de redes de cuidado territoriais e visando recursos que possam garantir o direito a vida (9-10).

Sendo assim, historicamente, essa estratégia de cuidado, é assumida em 1994 pelo Ministério da Saúde como estratégia no campo da prevenção das DST/AIDS e também em reduzir os danos causados pelo uso prejudicial de AD; resgatando o papel do usuário de fortalecimento do seu protagonismo, sem a exigência imediata e automática de abstinência; partindo do pressuposto de singularidades e trata-se como um método (caminho) de cuidado não excludente (9-10).

O Programa de Atenção aos Usuários de Álcool e outras Drogas é regulamentado por meio da Portaria 816/2002. Outras portarias que garantem 0 acesso dos usuários aos serviços de saúde inseridos na comunidade é a 336/2002 - CAPS AD, Programa Saúde da Família, Programa de Agentes Comunitários ${ }^{(9-12)}$.

O Programa considera ainda a atenção fortalecida por uma rede assistencial inserida na comunidade, com ênfase na reabilitação e reinserção desses sujeitos sem o estigma social decorrente do uso, associado a RPB (9-10).

Os serviços de atenção - CAPS AD, devem prestar acolhimento diariamente, ofertar leito de retaguarda, ter acesso as vagas de internação em hospitais gerais, com retaguarda psiquiátrica; em âmbito singular. Devem 
trabalhar de maneira articulada com outros dispositivos de cuidado em saúde mental e na atenção primária à saúde ${ }^{(9-10)}$.

As ações de Redução de Danos devem contemplar os seguintes âmbitos - individual, familiar, relações interpessoais e ambientes de formação e aprendizado. Devem também permitir maior flexibilização de projetos terapêuticos, adequados a necessidade de cada sujeito (9-11).

Frente ao cenário exposto anteriormente, a não assistência permeada pelos preceitos da reforma psiquiátrica brasileira e diretrizes do SUS possibilitou o cuidado aos usuários de álcool e outras drogas pelas "Comunidades Terapêuticas". Serviços nem sempre regulamentados e preparados para o nível de complexidade do cuidado em saúde. Ressalta-se que é de responsabilidade da Agência Nacional de Vigilância Sanitária (ANVISA) o monitoramento e vigilância desses dispositivos criados para a atenção às pessoas (9-10).

Por fim, a Portaria oㅡ 3088/GM, de 23 de dezembro de 2011, instituiu a Rede de Atenção Psicossocial (RAPS) para atenção às pessoas com transtorno mental ou dependentes de crack, álcool e outras drogas, no âmbito do SUS. Os objetivos gerais RAPS são: ampliar o acesso à atenção psicossocial da população em geral, promover a vinculação das pessoas com transtornos mentais e com abuso do uso de crack, álcool e outras drogas e suas famílias e garantir a articulação e integração dos pontos de atenção das redes de saúde no território, qualificando a assistência por meio do acolhimento, do acompanhamento contínuo e da atenção às urgências (9-10).

\subsubsection{Serviços Comunitários de Saúde Mental}

Como foi explicitado anteriormente, mudanças na legislação, como a implantação da Lei 10.216 (de 06 de abril de 2001), possibilitaram a ratificação das diretrizes constituintes do SUS, o que garantiu aos usuários do serviço de saúde mental a universalidade de acesso e direito à assistência e a integralidade do cuidado ${ }^{(13)}$.

No Brasil, os CAPS foram implantados, como resultado do movimento denominado Reforma Psiquiátrica, para articularem a Rede de Saúde Mental no território onde estão implantados. Esses serviços (13) são substitutivos aos hospitais psiquiátricos, que têm por objetivos: dar atendimento clínico diário, a 
fim de evitar as internações; promover a inserção social das pessoas com transtornos mentais; constituir-se em porta de entrada à rede de atenção especializada; e proporcionar suporte em saúde mental, focando no desenvolvimento de autonomia (14).

Nesse contexto, essa mudança paradigmática deve englobar a relação que se estabelece com o usuário, equipe, família e a comunidade. A mudança de papéis, a democratização das instituições, o envolvimento e responsabilização da comunidade devem somar-se aos objetivos técnicos do tratamento. O objeto de intervenção torna-se mais complexo e interdisciplinar, assim como as práticas e os saberes tradicionais devem ser reconstruídos para responder a essa transformação ${ }^{(14)}$.

Uma das mudanças paradigmáticas propostas pela Reforma Psiquiátrica com a criação do CAPS como serviço substitutivo ao hospital psiquiátrico foi sua inserção no território do sujeito. Território aqui compreendido como esferas dinâmicas do contexto singular de cada um (13-14).

Este fator é determinante, uma vez que o CAPS deve trabalhar com serviços de saúde/social/cultural e de lazer, além das redes que fazem parte da interface da pessoa que sofre ${ }^{(13)}$.

O primeiro CAPS fundado no Brasil em 1986 foi o CAPS Professor Luiz da Rocha Cerqueira, localizado na Rua Itapeva, em São Paulo. Logo foram sendo criados outros serviços substitutivos, como os Núcleos de Atenção Psicossocial (NAPS), em Santos e Ribeirão Preto e os Centros de Referência em Saúde Mental (CERSAM's), em Belo Horizonte. Todos os dispositivos estão inseridos no SUS, são regulamentados pela Portaria GM 224/92 e são definidos por espaços de cuidado que as pessoas acessam para seguimento ambulatorial ou internação por equipe multidisciplinar (13).

A Portaria ampliou o cuidado ofertado pelos serviços, dada sua complexidade tendo por missão a reabilitação psicossocial e cuidados clínicos de pessoas que sofrem por transtornos mentais graves e persistentes, garantindo o direito à cidadania e a reinserção social do sujeito e de sua família (13-14).

O CAPS, sendo um serviço inserido nas diretrizes do SUS, é um espaço de tratamento e referência, que garante ao sujeito cuidado comunitário, cuidado intensivo, singular e promoção de saúde ${ }^{(14)}$. 
O serviço tem como objetivos prestar atendimento diário; gerenciar os projetos terapêuticos ofertando cuidado clínico e singular; promover a reinserção social por meio de ações no território que perpassam esferas da saúde, como: educação; trabalho; esporte; cultura e lazer; matriciar atenção primária à saúde; supervisionar os hospitais psiquiátricos territoriais; entre outras ${ }^{(13)}$.

O espaço físico do serviço deve estar preparado, a fim de compor com sua proposta terapêutica - salas para atendimento individual e em grupo, refeitório, sanitários, espaços de convivência e oficinas; além de espaços no território para outras práticas de cuidado (13).

As pessoas atendidas nos CAPS são aquelas com sofrimento psíquico, que não conseguem realizar seus projetos de vida em decorrência do sofrimento. Sendo assim, são aquelas com transtornos mentais graves e persistentes, incluindo as pessoas que sofrem por uso de álcool e outras drogas e crianças e jovens ${ }^{(14)}$.

Os usuários acessam o serviço diretamente ou são encaminhadas e/ou buscam as Unidades Básicas de Saúde (UBS) do território. Inicialmente, no CAPS é realizado um acolhimento dessa pessoa, que pode estar acompanhada ou não. No acolhimento, o objetivo é ofertar uma escuta qualificada do sofrimento, a fim de colher o máximo de informações e dar seguimento ao cuidado ${ }^{(14)}$.

Caso a pessoa que buscou atendimento não necessite do CAPS ou não deseje fazer acompanhamento no serviço, ela deverá ser encaminhada a outro espaço de cuidado em que possa ser beneficiada. Caso a pessoa esteja impossibilitada, um profissional do CAPS poderá realizar o atendimento em seu domicílio, acompanhado por um profissional da UBS/ Estratégia Saúde da Família (ESF) ${ }^{(13) .}$

Ao traçar-se o Projeto Terapêutico Singular (PTS), tem inicio o vínculo de cuidado e as atividades terapêuticas. Todo usuário atendido no serviço terá um profissional de referência. Este é responsável por acompanhar o sujeito de um modo mais próximo, repensar o PTS quando necessário, avaliando as metas e os objetivos alcançados ou que surgirem. O profissional de referência também é responsável por intermediar a comunicação entre a equipe e o sujeito (13).

De acordo com a Portaria GM 336/02, o cuidado que o serviço deve prestar pode ser definido como: Intensivo (usuários que necessitam do serviço 
diariamente, que estão em crise ou com extrema dificuldade de convívio social, necessitando de atenção continuada); Semi-Intensivo (usuários atendidos até 12 dias por mês, nos quais o sujeito se encontra melhor frente ao convívio social, embora ainda necessite de suporte da equipe) e Não Intensivo (usuários que possam ser atendidos até três dias no mês e que não necessitem de atendimento contínuo da equipe) ${ }^{(13)}$.

Por sua vez, cada CAPS deve ter o seu projeto terapêutico, no qual devem ser consideradas as particularidades do território, contribuições da equipe interdisciplinar, dos usuários e familiares que ali estão inseridos ${ }^{(14)}$.

As atividades terapêuticas ofertadas pelos CAPS devem ser singulares e únicas, construídas em conjunto com comunidade, usuários e familiares. $\mathrm{O}$ atendimento à crise também é uma modalidade de oferta de cuidado, uma vez que os serviços devem evitar internações hospitalares ${ }^{(13)}$.

A oferta de atividades estratégicas e terapêuticas deve compor as seguintes esferas: atendimento para os familiares, atendimento individual, atendimento em grupo, atividades comunitárias, assembleias e/ou reuniões de organização e planejamento do serviço ${ }^{(14)}$.

O cuidado do CAPS e seu funcionamento se dão em diferenças tipos de serviços: CAPS I (Cinco dias na semana, municípios de 20.000 à 70.000 habitantes); CAPS II (Cinco dias na semana, municípios de 70.000 à 200.000 habitantes); CAPS IIII (24 horas, incluindo finais de semana e feriados, municípios com mais de 200.000 habitantes); CAPS i (municípios acima de 150.000 habitantes), CAPS AD (municípios acima de 70.000 habitantes) e CAPS AD III (municípios acima de 200.000 habitantes) ${ }^{(13)}$.

O funcionamento do CAPS por 24 horas permite o acolhimento noturno do sujeito que se encontra em grave sofrimento psíquico, a fim de evitar hospitalização (13-14).

Os CAPS AD começaram a ser implantados em 2002. Devem fornecer os cuidados descritos anteriormente as pessoas com transtornos graves $\mathrm{e}$ persistente, decorrentes do uso de álcool e outras drogas. Também devem fornecer leito para desintoxicação ambulatorial, a fim de evitar internações hospitalares ${ }^{(14)}$. 
Além do cuidado ofertado por meio do PTS, os CAPS AD devem promover ações de prevenção e promoção à saúde; além de estreitar laços com hospitais gerais, uma vez que necessitam de retaguarda clínica ${ }^{(13)}$.

Os CAPS devem estar em constante articulação com os serviços da atenção primária à saúde. Serviços esses que estão inseridos no território e na comunidade do sujeito que sofre psiquicamente e que necessita de "apoio matricial" (13).

Matriciamento ou apoio matricial é um modelo de cuidado em saúde, no qual uma ou duas equipes por meio da ação da construção compartilhada criam ações terapêuticas, a fim de promover o cuidado de cada sujeito. Sendo assim, consiste nas articulações, atividades realizadas em conjunto, a discussão e supervisão de casos de usuários, visitas domiciliares e entre outras atividades a fim de garantir saúde de forma integral a cada sujeito que se beneficie por tais ações ${ }^{(13)}$.

Por fim, salientamos para a importância do protagonismo do usuário no CAPS, a fim de garantir a promoção de sua saúde e sua reabilitação psicossocial (13).

\subsubsection{Mulheres e Álcool e Outras Drogas}

A questão do uso de álcool e outras drogas é uma problemática de saúde pública mundial. Com relação a diferença de gênero, nota-se que os padrões de consumo de álcool, tabaco e outras drogas das mulheres têm se aproximado aos padrões dos homens ${ }^{(15)}$.

Mulheres apresentam maior prevalência de abstinência (59\%) e os homens bebem mais frequentemente, ou seja, 39\% dos homens bebem pelo menos $1 \mathrm{vez} /$ semana, dos quais $11 \%$ bebem diariamente. A quantidade de bebida por ocasião de consumo também difere conforme o sexo, ou seja, enquanto a maioria das mulheres (68\%) bebeu até 2 doses de álcool na última ocasião, $38 \%$ dos homens beberam 5 ou mais doses, dos quais $11 \%$ beberam 12 ou mais doses na última ocasião (58).

Estudos epidemiológicos nacionais (5) demonstram um crescente aumento de mulheres dependentes de álcool e outras drogas, considerando alta 
prevalência de problemas relacionados ao consumo nesse recorte de gênero (1516).

A diferença em dados entre os tipos de bebidas alcóolicas entre homens e mulheres, percebemos que mulheres bebem mais vinho que os homens, em contrapartida, os homens bebem mais destilados que as mulheres. Com relação ao uso de destilados, é feito preferentemente na forma de cachaça (66\%) e prevalentemente nas regiões Norte, Nordeste e Centro-Oeste e por pessoas de baixa condição socioeconômica (31\%) ${ }^{(58)}$.

A literatura também nos mostra que $12 \%$ das mulheres fazem o uso de bebidas alcóolicas em padrão binge, enquanto que $21 \%$ dos homens também (referenciar). Com relação a dependência, 17,1\% dos homens e 5,7\% das mulheres são dependentes. O número maior de dependentes está nas faixas etária dos 18 aos 24 anos em que 23,7\% dos homens e 7,4\% das mulheres são considerados dependentes ${ }^{(59)}$.

No ano de 2005, o CEBRID realizou a segunda versão do estudo, intitulado de "Il Levantamento Domiciliar sobre Uso de Drogas Psicotrópicas no Brasil - 2005", visando o panorama geral de uso de álcool e outras drogas na sociedade brasileira e de notar possíveis flutuações na prevalência de uso dessas substâncias. A pesquisa indicou que o número de brasileiros, com idades entre 12 e 65 anos, dependentes de bebidas alcoólicas foi de 12,3\%, o que corresponde à população de 5.799 .005 pessoas ${ }^{(59)}$.

A comparação das duas pesquisas permitiu observar um agravamento nos indicadores de uso de álcool. No I Levantamento Domiciliar a prevalência de dependência de álcool foi de $11,2 \%$ na população geral, sendo de $17,1 \%$ entre homens maiores de 12 anos e de 5,2\% na faixa dos 12 aos 17 anos. No II Levantamento a estimativa de dependentes de álcool foi de $12,3 \%$, sendo de $19,5 \%$ entre homens e de 6,9\% entre mulheres. Os dados também indicaram aumento do consumo de álcool em faixas etárias cada vez mais precoces. Em 2001, o número de dependentes na faixa de 12 a 17 anos foi de 5,2\% contra 7\% em 2005. O estudo constatou também que o maior número de dependentes de bebidas alcoólicas continua sendo do sexo masculino na faixa etária entre $18 \mathrm{e}$ 24 anos, o percentual foi de 23,7\% (2001) e 27,4\% (2005). O número de pessoas que procuraram tratamento reduziu de 4\% em 2001 para 2,9\% em 2005, respectivamente de 1,9 milhão de pessoas para 1,4 milhão ${ }^{(59)}$. 
Mudanças políticas e culturais ocorridas no final do século XX, trouxeram para a população feminina maior inserção no mercado de trabalho e, logo, aumento do número de famílias chefiadas por mulheres. Neste sentido, as mulheres passaram a estar expostas aos mesmos riscos sociais que os homens, dentre eles o consumo de substâncias psicoativas ${ }^{(15)}$.

Esse fato vai do encontro com a problemática aqui proposta a estudar. Mulheres consumindo mais substâncias psicoativas permeia a complexidade de tal fenômeno - relações sociais e meio no qual estão inseridas. Podemos pensar e refletir acerca do papel da mulher na sociedade, no qual este possa estar lhe causando sofrimento psíquico ${ }^{(15)}$.

Vale ressaltar que a imagem e o papel das mulheres na sociedade contemporânea não estão associados ao estereótipo de usuárias de álcool e outras drogas. E essa circunstância contribui para a invisibilidade das mulheres nesse contexto, aumento os agravos em sua saúde (15).

De acordo com Zanello (21,22):

[...] podemos encontrar nestes dados importantes questões de gênero [...]. Pela escuta dessas mulheres podemos afirmar: o álcool é visto como um problema que precisa ser resolvido porque coloca em xeque os papéis sociais masculinos. Isto é, interrompe o ciclo laboral, o rendimento, a virilidade esperada de um homem, em todos os âmbitos nos quais ele participa. Já o Diazepam é um medicamento que permite as mulheres continuarem cumprindo seu papel social: ser cuidadora dos filhos, do lar, aceitar a subjugação social e sexual de seus parceiros etc. Enfim, há uma perversidade no sistema, na qual as relações de gênero são tornadas invisíveis [...] (p.315).

Partimos do conceito de saúde, referente ao processo saúde-doença, no qual saúde não significa apenas a ausência de doenças e sim, manutenção da qualidade de vida e ética no modo de viver das mulheres ${ }^{(15)}$.

Estudos realizados em CAPS no Brasil, com enfoque do gênero feminino retratam um pouco da caracterização das mulheres que fazem uso/uso abusivo de álcool e outras drogas. Um ponto de destaque importante a ser analisado e refletido é com relação ao início precoce de uso - a influência familiar acerca do consumo de álcool (18).

No mesmo estudo, outro fator no qual foi dado importância é aos sentimentos gerados no passado e no presente com relação ao consumo da 
droga. Brigas, desavenças e violências familiares são propiciadores ao uso da substância psicoativa. Após o início do consumo de álcool e outras drogas são destacados perda dos laços de afetividade/familiares e fragilidades no relacionamento interpessoal ${ }^{(18)}$.

Serviços comunitários em saúde mental e política de álcool e outras drogas devem estar preparados para acolher a demanda das mulheres, priorizando as necessidades singulares de gênero como: estigma social, derivado de uma cultura sexista no qual estão inseridas; dificuldades ao buscar tratamento (filhos, casamento), maior frequência de riscos sexuais, entre outros (18).

Frente a isso, as práticas em saúde devem ser substituídas por ações que alcancem o cuidado psicossocial, comprometido com as demandas psíquicas e sociais das mulheres, refletindo e corroborando com as diferenças de gênero aqui apontadas ${ }^{(19)}$.

Outra contribuição do mesmo estudo foi com relação a adesão das mulheres ao tratamento, uma vez que o olhar para essas pessoas deve ser individual, familiar e social; garantindo maior efetividade e favorecendo o processo terapêutico ${ }^{(19)}$.

Assim, faz-se necessário o conhecimento da inserção das mulheres na sociedade, enquanto sujeito; a compreensão das relações sociais que as mesmas estabelecem e das desigualdades de gênero que permeiam as relações e que são enfrentadas a fim de auxiliar a compreensão do fenômeno das drogas (15-18).

O cuidado em Saúde Mental deve ser de forma integral e singular; conhecer a trajetória das mulheres permite identificar os significados expressos pelas mesmas, a fim de contribuir para o planejamento do processo terapêutico (15-18-19).

\section{Justificativa do estudo e Objetivos}

\subsection{Justificativa do Estudo}

Estudos feministas com a problemática do gênero emergiram nos anos de 1960 e 1970 com o intuito de refletir e desconstruir a lógica do feminino frente 
às posições sociais desprivilegiadas às quais eram destinadas as mulheres (20). Os mesmos estudos também promoveram uma discussão da impossibilidade de pesquisar homens e mulheres, separadamente, invisiabilizando a relação existente ${ }^{(21)}$.

Os estereótipos sociais promovem a desigualdade e o poder hierárquico entre os gêneros, validando valores sociais e a constituição dos espaços privilegiados diferentes ${ }^{(21)}$.

A moralização do ser feminino permeia valores éticos atribuidos ao papel da mulher na sociedade em que estamos inseridos (21). Em nosso convívio, gênero é assumido pelo sistema patriarcal no qual as mulheres são, historicamente, deixadas à margem da sociedade (22).

$O$ recorte de gênero feminino e a relação com o uso/uso abusivo de álcool e outras drogas faz-se necessário. As mulheres são consideradas como uma parcela excluída da população, com necessidades singulares e que nem sempre são atendidas frente a tal demanda (15).

O uso de drogas por mulheres está associado ao contexto cultural, social, familiar e individual em que estão inseridas. Além disso, tais contextos estão intimamente associados aos riscos que as mulheres se sujeitam, em decorrência do consumo de substâncias psicoativas ${ }^{(15)}$.

Mulheres dependentes de álcool e outras drogas aderem menos ao tratamento do que os homens ${ }^{(22)}$. Anuncia a diferença entre os gêneros, sendo os homens por apresentarem mais problemas legais e profissionais, e as mulheres por mais problemas físicos e familiares.

Ainda com relação as mulheres, são identificados fatores associados ao consumo como: abuso sexual, violência doméstica, preocupação com os filhos, preocupação com o corpo e baixa auto-estima. Tais fatores justificam ainda mais a especificidade de acompanhamento de tal população (15).

Assim, pergunta-se como se dá o acesso de mulheres à atenção integral em saúde aos usuários de álcool e outras drogas?

\subsection{Objetivos}

\subsubsection{Objetivo Geral}


O presente estudo tem por objetivo geral realizar uma revisão de escopo acerca do acesso das mulheres em serviços comunitários de saúde mental em álcool e outras drogas.

\subsubsection{Objetivo Específico}

Examinar e mapear a área de conhecimento acerca do acesso das mulheres em serviços comunitários de saúde mental álcool e outras drogas.

\section{Metodologia}

A Prática Baseada em Evidências (PBE) é uma perspectiva metodológica que tem como propósito discorrer de um problema identificado, realizar uma busca bibliográfica e analisar as evidências disponíveis quanto ao tema do problema. Após tal, executar as evidências disponíveis e avaliá-las quanto ao resultado; o que possibilita uma melhor assistência de saúde à população (24).

As revisões de escopo apresentam como primeira referência para a escrita em 2005; embora seja considerada uma nova prática de revisão; não tem uma definição universal de um método ${ }^{(25)}$.

Revisões de escopo são vantajosas quando se faz necessário sintetizar evidências de pesquisa, além de utilizadas com o fim de mapear a literatura existente em um determinado contexto. Além disso, também podem ser utilizadas para resumir e disseminar resultados de pesquisas ${ }^{(25)}$.

Tradicionalmente, revisões sistemáticas são utilizadas para agregar literatura quantitativa acerca de uma condição ou uma intervenção particular a fim de responder perguntas de eficiência. Logo, as revisões de escopo, sendo uma metodologia de pesquisa do Joanna Briggs Institute (JBI), se preocupa também com evidências qualitativas ${ }^{(25)}$.

Dessa forma, as revisões de escopo possuem uma abordagem mais ampla com o objetivo de mapear literatura, permitindo assim questões de pesquisas mais vastas. O objetivo por sua vez, das revisões de escopo é de mapear os conceitos chaves em uma determinada área de pesquisa (25).

O valor da Revisão de Escopo dá-se pela identificação de lacunas no banco de conhecimento da pesquisa, esclarecendo conceitos chaves e relatando 
os tipos de evidência relacionados ao tema e informar a prática no campo (25). Dessa forma, optou-se por esse método ao se tratar do acesso de mulheres em serviços comunitários de saúde mental em álcool e outras drogas.

Esse tipo de metodologia de revisão permite a inclusão de uma variedade de modelos de estudos. Também são estruturadas de modo a ofertar uma visão da evidência existente sem se preocupar com a qualidade dos estudos; ou seja; uma avaliação formal da qualidade metodológica dos estudos incluídos geralmente não é realizada (25).

Para a elaboração da presente revisão, foi seguido as etapas metodológicas segundo o Manual do Revisor da Joanna Briggs Institute (JBI). A organização proposta Arksey e O'Malley (2005) ${ }^{(60)}$ para o seguimento dass revisões de escopo foram bem utilizadas por pesquisadores; além da reformulação da organização de Levac, Colquhoun e O'Brien (2010) (28).

No quadro 1 está explicito a organização das estapas do seguimento de revisões de escopo segundo o Manual do Revisor do JBI. Ambas as organizações foram elaboradas no desenvolvimento da temática do JBI a fim de seguimento de revisões de escopo (peters, et.al, 2015).

Quadro 1. Etapas da Revisão Sistemática de Escopo, segundo o Manual do Revisor da JBI - São Paulo, SP, Brasil, 2018.

\begin{tabular}{|c|c|c|c|}
\hline & $\begin{array}{l}\text { Quadro Arksey e } \\
\text { O'Malley (11) }\end{array}$ & $\begin{array}{l}\text { Melhorias propostas } \\
\text { por Levac, Colquhoun } \\
\text { e O'Brien (11) }\end{array}$ & $\begin{array}{l}\text { Melhorias } \\
\text { propostas por } \\
\text { Peters et al (60) }\end{array}$ \\
\hline 1. & $\begin{array}{l}\text { Identificando a questão } \\
\text { da pesquisa }\end{array}$ & $\begin{array}{l}\text { Clarificando e ligando o } \\
\text { propósito e questão de } \\
\text { pesquisa. }\end{array}$ & $\begin{array}{l}\text { Definir e alinhas o } \\
\text { (s) objetivo (s), a } \\
\text { (s) pergunta (s) da } \\
\text { revisão }\end{array}$ \\
\hline 2. & $\begin{array}{l}\text { Identificando estudos } \\
\text { relevantes }\end{array}$ & $\begin{array}{l}\text { Balanceando viabilidade } \\
\text { com amplitude e } \\
\text { Abrangência do escopo } \\
\text { processo }\end{array}$ & $\begin{array}{l}\text { Desenvolver e } \\
\text { alinhar os critérios } \\
\text { de inclusão com o } \\
\text { objetivo (s), a (s) } \\
\text { pergunta (s) da } \\
\text { revisão }\end{array}$ \\
\hline 3. & Seleção de estudo & $\begin{array}{l}\text { Utilizar uma abordagem } \\
\text { para selecionar estudos } \\
\text { e extrair os dados }\end{array}$ & $\begin{array}{ll}\text { Descrever } & \text { uma } \\
\text { abordagem } \\
\text { planejada } \\
\text { pesquisar, } \\
\text { selecionar, extrair } \\
\text { e desenhar } \\
\text { gráficos }\end{array}$ \\
\hline
\end{tabular}




\begin{tabular}{|c|c|c|c|}
\hline 4. & Mapeando os dados & $\begin{array}{l}\text { Incorporando um resumo } \\
\text { numérico e Análise } \\
\text { temática qualitativa }\end{array}$ & $\begin{array}{l}\text { Procurar } \\
\text { evidências }\end{array}$ \\
\hline 5. & $\begin{array}{ll}\text { Agrupar, } & \text { resumir } \\
\text { relatar os resultados }\end{array}$ & $\begin{array}{l}\text { Identificando as } \\
\text { implicações do estudo; } \\
\text { resultados para política, } \\
\text { prática ou pesquisa. }\end{array}$ & $\begin{array}{l}\text { Selecionar } \\
\text { evidências }\end{array}$ \\
\hline 6. & Consulta (opcional) & 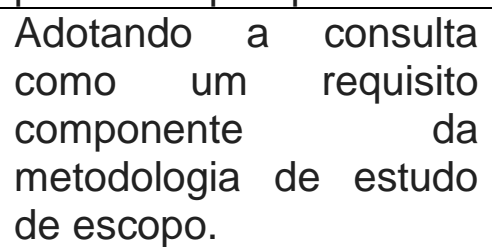 & Extrair evidências \\
\hline 7. & ------------ & & $\begin{array}{l}\text { Construir } \\
\text { Evidências }\end{array}$ \\
\hline 8. & 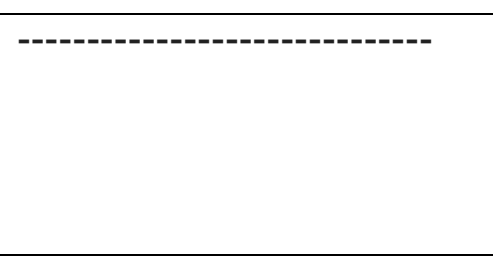 & 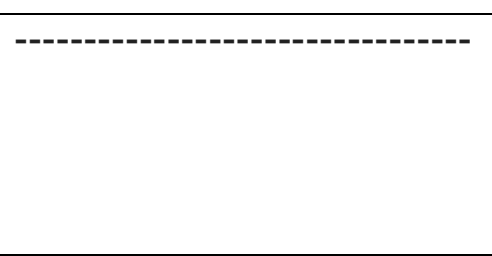 & $\begin{array}{l}\text { Sumarizar as } \\
\text { evidências em } \\
\text { relação ao objetivo } \\
\text { (s), a (s) pergunta } \\
\text { (s) da revisão }\end{array}$ \\
\hline 9. & ----------------------------- & 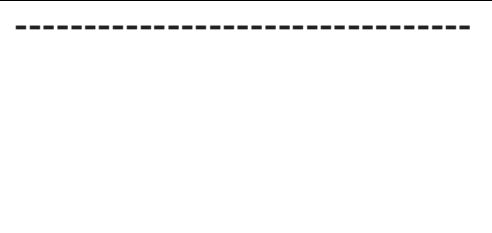 & $\begin{array}{lr}\text { Consultar } & \text { as } \\
\text { informações } & \text { dos } \\
\text { cientistas, } & \\
\text { bibliotecários } & \text { e/ou } \\
\text { especialistas } & \end{array}$ \\
\hline
\end{tabular}

\subsection{Etapas da Revisão de Escopo}

Discorre-se então de uma Revisão de Escopo que custeia a PBE com etapas pré-estabelecidas. O estudo de escopo ${ }^{(26)}$ - Scoping Study ou Scoping Review - têm como propósitos desenhar os conceitos que sustentam uma determinada área do conhecimento; investigar a profundidade, a relevância e natureza da análise; extrair e revelar dos dados encontrados, por fim, identificando as lacunas de pesquisas existentes.

Dessa forma, esse tipo de metodologia permite que o foco do pesquisador seja em apenas um propósito descrito acima ou em um conjunto dos mesmos. Pode também ser utilizado para realizar um mapeamento do conhecimento a ser estudado antes da aplicação do método da revisão sistemática, por exemplo (25).

No presente estudo, a utilização da revisão de escopo como metodologia foi elaborada de maneira independente; ou seja; foi utilizada para investigar uma determinada área do conhecimento a fim de encontrar lacunas de pesquisa, 
esclarecer conceitos importantes e divulgar as evidências disponíveis com relação à prática da temática ${ }^{(25-27)}$.

As revisões sistemáticas do JBI (25-27) iniciam-se com o seguimento de um protocolo, permeado por critérios de inclusão e exclusão, que se associam com os objetivos e pergunta norteadora. Entretanto, a especificidade do estudo de escopo é pela abrangência dos critérios de inclusão estabelecidos.

Um fator metodológico importante neste tipo de revisão é a inclusão de uma gama maior de evidências disponíveis acerca da temática estudada; ou seja; trabalhos quantitativos e/ou qualitativos (25-28).

Além da maior gama de critérios de inclusão de evidências, também há uma possibilidade do objetivo da investigação ser mais abrangente; reunindo assim, evidências de fontes diferentes e heterogêneas. A finalidade então é de mapear todas as evidências disponíveis ${ }^{(25-27)}$.

Por fim, anterior a elaboração da revisão de escopo, não foram identificados protocolos e/ou revisões nas bases de dados aqui selecionadas e nem no Banco de Dados da JBI de revisões sistemáticas, com a mesma temática proposta no presente estudo, sendo utilizados os termos: Community Mental Health Care, Women; Disorders Related to Substance Use e Nursing.

\subsection{Questões Norteadoras}

Para a elaboração das estratégias de busca bibliográfica foi utilizada uma adaptação da estratégia PICO (P: sujeito; I: intervenção; C: comparação e O: desfecho). Tal estratégia possibilita ao pesquisador a elaboração da pergunta de pesquisa, da busca bibliográfica a fim de encontrar a melhor informação científica disponível naquele momento ${ }^{(26)}$.

Para a formulação da questão norteadora do estudo e objetivar os elementos metodológicos fundamentais, utilizamos a pergunta PCC, a estratégia PICO adaptada. Assim, na adaptação, tal acrômio significa $\mathrm{P}$ - população, C conceito e C - contexto/desfecho ${ }^{(26-27)}$.

Sendo assim, a estratégia foi formulada da seguinte maneira: $P$ - gênero feminino; C -acesso das mulheres aos serviços e C - Atenção Integral a mulheres usuárias de álcool e outras drogas. 
Mais especificamente buscamos responder a seguinte indagação: quais são as barreiras que influenciam 0 acesso das mulheres em serviços comunitários de saúde mental em álcool e outras drogas?

\subsection{Critérios de Inclusão}

Os critérios de inclusão que aqui discorremos são: tipos de participantes, conceito, contexto e quais as fontes que foram usadas. Vale ressaltar que tais critérios de inclusão correspondem à equivalência com a estratégia para formulação da questão norteadora (25).

Logo, como tipo de participante utilizou-se gênero feminino, mulheres adultas; o conceito ou o fenômeno de interesse o acesso das mulheres ao cuidado e o contexto correspondeu a atenção integral de cuidados em serviços comunitários em álcool e outras drogas.

Por fim, foram selecionados trabalhos de qualquer natureza metodológica - quantitativa e/ou qualitativa; em três idiomas - português, inglês e espanhol e sem delimitação de tempo pois ao se tratar de uma revisão de escopo, é desejável uma ampla gama de trabalhos para compor a busca inicial.

\subsection{Estratégia de Pesquisa e Palavras Chaves}

Foram consultadas sete bases de dados, sendo: Biblioteca Virtual em Saúde (BVS), US National Library of Medicine National Institutes of Health (Pubmed), Web of Science, SciVerseScopus (Scopus), American Psychological Association (Psyinfo), Cumulative Index to Nursing and Allied Health Literature (Cinahal), Index Psy Periódicos (indexpsy) e EMBASE.

No quadro 02 encontram-se descritas as estretégias de busca utilizadas em cada base de dados.

Quadro 02. Dados iniciais da data da pesquisa bibliográfica, base de dados e estratégia de pesquisa utilizada - São Paulo, SP, Brasil, 2018. 


\begin{tabular}{|c|c|c|}
\hline $\begin{array}{ll}\text { Data da } \\
\text { Pesquisa }\end{array}$ & Base de dados & Estratégia de Pesquisa \\
\hline $17 / 07 / 2018$ & Psyinfo & $\begin{array}{l}\text { \{Community Mental Health Services\} AND } \\
\text { (Any Field: female OR Any Field: wom?n) } \\
\text { AND (Any Field: Accessibility OR Any Field: } \\
\text { access) AND (Any Field: alcohol OR Any } \\
\text { Field: "substance abuse") }\end{array}$ \\
\hline $17 / 07 / 2018$ & Cinahal & $\begin{array}{l}\text { (MH "Health Services Accessibility+") AND } \\
\text { (MH "Female") OR TI female OR female OR } \\
\text { AB woman OR TI woman OR TI women OR } \\
\text { AB women AND (MH "Community Mental } \\
\text { Health Services") OR TI "Community Mental } \\
\text { Health Services" OR AB "Community Mental } \\
\text { Health Services" }\end{array}$ \\
\hline $17 / 07 / 2018$ & Scopus & $\begin{array}{l}\text { ( TITLE-ABS-KEY ( "Health Services } \\
\text { Accessibility" ) ) AND ( TITLE-ABS-KEY ( } \\
\text { "Community Mental Health Services" ) ) AND } \\
\text { ( TITLE-ABS-KEY ( female OR wom?n ) ) }\end{array}$ \\
\hline 29/08/2018 & Indexpsiperiódicos & $\begin{array}{l}\text { (mulher }^{*} \text { OR feminin } \\
\text { AND "saude mental" AND comunitaria }\end{array}$ \\
\hline $29 / 08 / 2018$ & BVS & $\begin{array}{l}\text { tw:((mulher* OR wom?n OR mujer*)) } \\
\text { AND (instance:"regional") AND ( } \\
\text { mh:("Serviços Comunitários de Saúde } \\
\text { Mental") AND mj:("Acesso aos } \\
\text { Serviços de Saúde")) }\end{array}$ \\
\hline $29 / 08 / 2018$ & Pubmed & 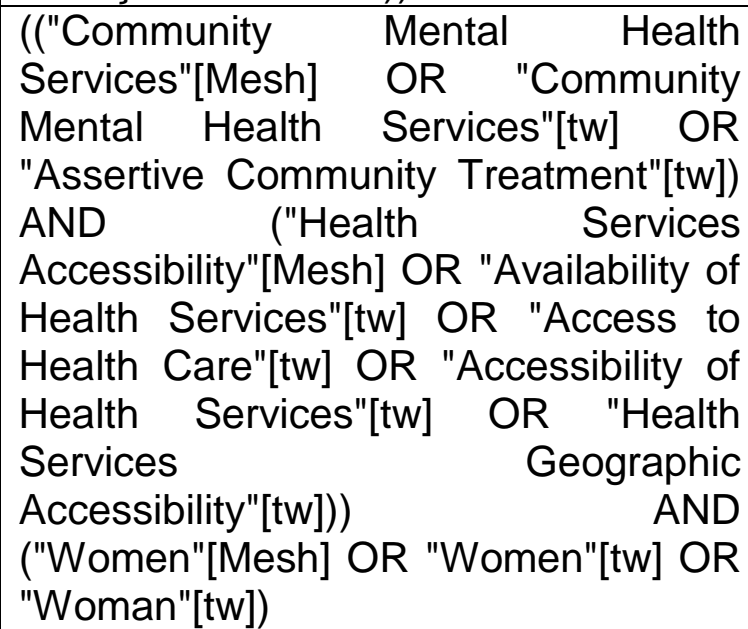 \\
\hline $29 / 08 / 2018$ & Embase & $\begin{array}{l}\text { ('community mental health service' } \\
\text { AND access }{ }^{*} \text { AND 'woman'/exp OR } \\
\text { woman OR 'women'/exp OR women } \\
\text { OR 'female'/exp OR female }\end{array}$ \\
\hline
\end{tabular}

\subsection{Seleção dos Estudos}

Realizada busca nas bases de dados conforme quadro 1, somou-se um quantitativo de 601 trabalhos. No quadro 03 estão apresentados os resultados em cada Base de dados. 
Quadro 03. Resultados iniciais da busca bibliográfica de acordo com a Base de dados - São Paulo, SP, Brasil, 2018.

\begin{tabular}{|l|l|}
\hline Base de dados & Quantitativo inicial de trabalhos \\
\hline Psyinfo & 30 trabalhos \\
\hline Cinahal & 195 trabalhos \\
\hline Scopus & 301 trabalhos \\
\hline Indexpsiperiódicos & 0 trabalhos \\
\hline BVS & 30 trabalhos \\
\hline Pubmed & 22 trabalhos \\
\hline Embase & 23 trabalhos \\
\hline
\end{tabular}

A seleção dos estudos deu-se por dois revisores independentes. Em um primeiro momento, foi realizada a leitura do título e do resumo dos trabalhos filtrados, sendo excluídos 512 estudos por não serem considerados potencialmente elegíveis. Os estudos que causaram dúvidas quanto à elegibilidade, foram mantidos para o segundo momento de coleta dos estudos.

No segundo momento da coleta realizou-se a leitura integral dos estudos potencialmente elegíveis, totalizando 89 trabalhos. Foi então efetuada a leitura integral de 89 estudos e a aplicação do formulário de extração de dados também por dois revisores independentes, dos quais foram excluídos 77 por não estarem relacionados a pergunta de pesquisa e os critérios de inclusão.

Com efeito, a presente revisão resultou em 12 estudos. Na Figura 01 está representado o fluxo das análises dos trabalhos.

Figura 1. Diagrama de fluxo da busca bibliográfica e inclusão de artigos. 

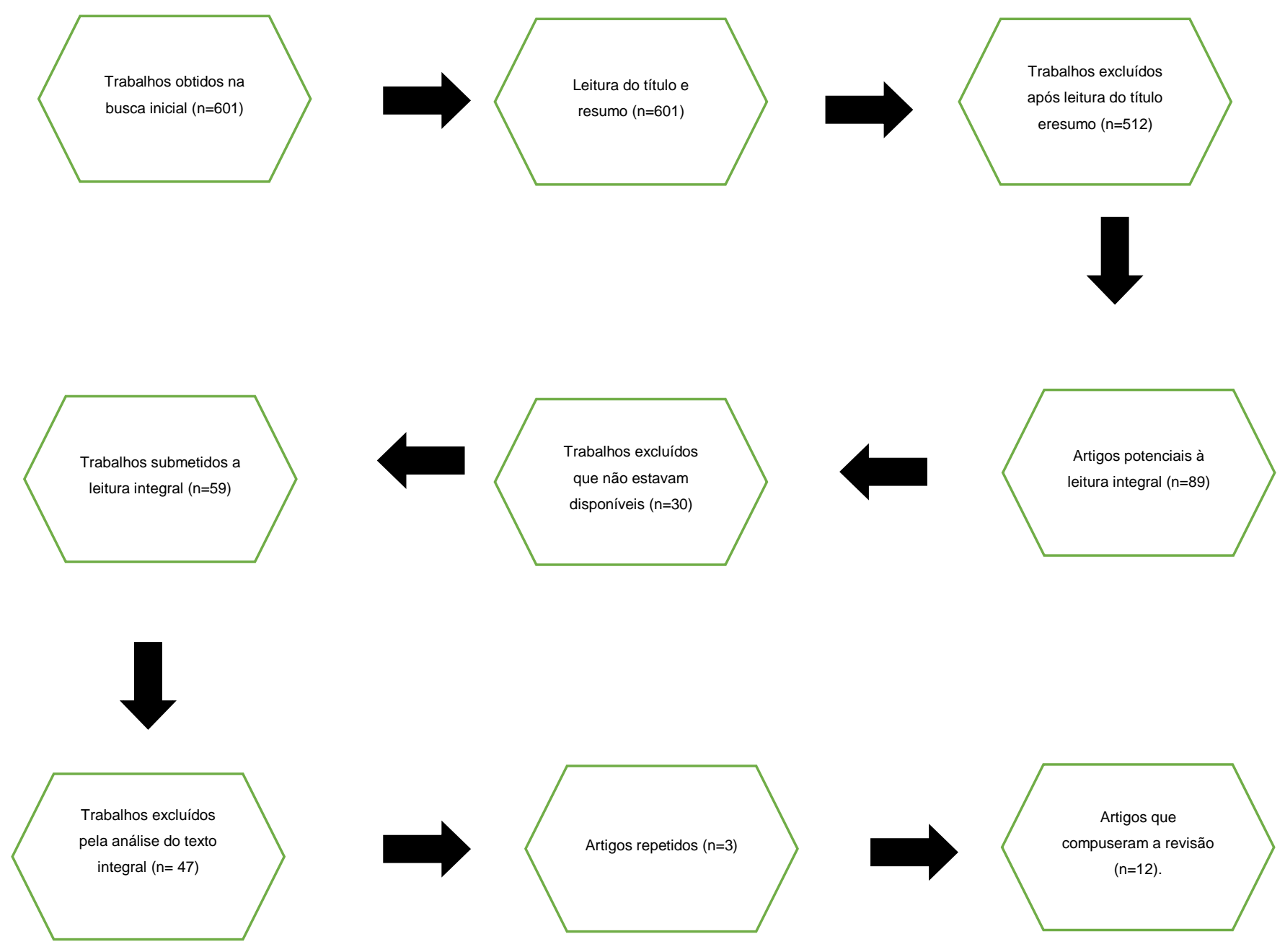

\subsection{Extração dos Resultados e Apresentação dos Resultados}

Para a extração dos dados dos trabalhos aqui incluídos por dois revisores independentes, utilizou-se um formulário de extração, nivelado aos objetivos da revisão, por meio de uma ferramenta desenvolvida especificamente para o presente trabalho, com base no manual do Revisor da JBI e que não houve necessidade de ajuste no decorrer de sua aplicação (25-27-28).

O formulário de extração de dados contempla as seguintes informações:

- Autor (es) do estudo;

- Ano de publicação do estudo;

- País de origem da publicação;

- População alvo;

- Objetivo e finalidade do estudo;

- Tamanho da amostra (se aplicável); 
- Metodologia;

- Conceito;

- Resultados e;

- Achados cabíveis a presente revisão.

O formulário foi aplicado em todos os trabalhos selecionados, originando o quadro 3, na apresentação dos resultados. Foi possível a identificação de dados referenciados a pergunta da pesquisa e aos objetivos da presente revisão de escopo com a utilização da ferramenta de extração de dados.

Por fim, os dados extraídos foram apresentados em categorias de análise conceituais e discorridos em meio ao referencial teórico.

\subsection{Referencial Teórico}

O referencial teórico utilizado foi de Joan Wallach Scott. Uma historiadora norte-americana que, em 1980, iniciou os estudos na trajetória das mulheres. A trajetória de discussão de gênero foi impulsionada apenas no século $X X^{(29)}$.

O termo gênero compõe uma construção de feministas contemporâneas como resultado da persistência das teorias existentes em esclarecer desigualdades entre homens e mulheres ${ }^{(29)}$.

A discussão em torno da desigualdade de gênero é algo complexo, com interface aos diversos setores sociais, como direitos individuais e das identidades de grupos. Sâo conceitos interligados e não opostos (29-30).

Posto esses conceitos interligados e não polarizados, destacamos que os sujeitos só podem ser analisados ao significá-los à singularidade. No entanto, o mesmo sujeito pertencente a um determinado grupo lhe é atribuido valor por estar inserido no grupo (29).

O gênero constitui-se como uma força social organizadora, um fator independente que aflige a saúde populacional, construindo desigualdades como sexo, classe social, idade, raça, nivel de escolaridade, entre outras ${ }^{(45)}$.

Para tal análise, Scott relata acerca de três grandes paradoxos acerca da igualdade de gênero: 1- A igualdade é um princípio absoluto e uma prática 
histórica circunstancial; 2- A identidade de um determinado grupo define os individuos, desprezando a expressão ou percepção total da singularidade e 3- A exclusão que ampara a discriminação é o pilar da negação e reprodução das demandas da inclusão ${ }^{(29)}$.

O termo igualdade significa a aceitação ou não da diferença e que caminhos são tomados com a sua consideração. A igualdade é analisada no âmbito econômico-social, racial, de gênero e outros setores da sociedade. Ademais, a diferença é usada a fim de organizar a vida social (29).

Historicamente a desigualdade de gênero deu-se quanto às questões anatômicas, mais precisamente os órgãos genitais definiram o ser cidadão e o ser não cidadão ${ }^{(29-30)}$. Vale a afirmação e discussão de Scott:

[...] Os homens eram indivíduos porque eram capazes de transcender o sexo; as mulheres não poderiam deixar de ser mulheres e, assim nunca poderiam alcançar o status de indivíduo. Não tendo semelhança com os homens, elas não poderiam ser consideradas iguais a eles e assim não poderiam ser cidadãs. É interessante notar aqui (...) que nesses argumentos aigualdade pertence a indivíduos e a exclusão a grupos; era pelo fato de pertencer a uma categoria de pessoas com características específicas que as mulheres não eramconsideradas iguais aos homens [...] (p.17).

Durante muitos anos, a função maternal das mulheres apresentou-se como uma justificativa para fortalecer e manter as mulheres excluídas do âmbito político, por exemplo (29-30).

Posto isso, vale uma reflexão acerca do modo como os processos de diferenciação social funcionam, objetivando o desenvolvimento de análises de desigualdade e discriminação que tratem as identidades sociais como processos politicos e sociais ${ }^{(29-30)}$.

Scott ${ }^{(29)}$ diz que "o gênero é um elemento constitutivo de relações sociais baseado nas diferenças percebidas entre os sexos, e o gênero é uma forma primeira de significar as relações de poder" (p. 21).

Modificações na organização das relações sociais equivalem a mudança nas relações de poder. Entretanto, essas modificações não são aplicadas em apenas um sentido ${ }^{(29)}$.

Há quatro elementos constitutivos das relações sociais acerca das diferenças entre os sexos, que são: símbolos culturalmente disponíveis; 
conceitos normativos; o fato de o gênero ser construido por meio do parentesco, embora não exclusivamente e a identidade subjetiva ${ }^{(29-30)}$.

Símbolos culturalmente disponíveis são os símbolos que recordam representações múltiplas, frequentemente contraditórias em diferentes contextos e modalidades diferentes ${ }^{(29)}$.

Por conceitos normativos entende-se as interpretações de sentido dos símbolos culturalmente disponíveis, que acabam por limitar as possibilidades metafóricas. Tais conceitos são manifestados em doutrinas religiosas, educativas, cientificas, políticas por exemplo. Dessa forma, assumem uma posição binária (masculino ou feminino) e afirmam o sentido de cada um (29). Gênero também é contruído pelo mercado de trabalho, pela educação, pelo sistema politico, entre outros contextos contemporâneos (29).

A construção do gênero por meio do parentesco promove o universo doméstico e a família como pilar da organização social. Vale ressaltar que, o gênero é construído por meio do parentesco, mas não apenas por ele.

Por fim, por identidade subjetiva entende-se como legitimação do gênero. Em outras palavras, existem as diferenças entre corpos que são relacionadas ao sexo biológico e as relações e fenômenos sociais que não são relacionados à sexualidade ${ }^{(29-30)}$.

Não podemos deixar de salientar a relação de autoridade e controle da mulher. Historicamente a diferença sexual foi nutrida pela dominação e controle sobre o feminino. Entretanto permite a compreensão da organização da igualdade e desigualdade entre os sexos (29-30).

Esse fator acima está intimamente direcionado a importância dada às mulheres quanto as "funções" maternas e reprodutivas apenas ${ }^{(29)}$.

Enfim, tal elaboração histórica de gênero promove uma reflexão quanto a redefinição e reestruturação do tema, visando a igualdade política e social não apenas do sexo, mas também, quanto as desigualdades de classe e raça ${ }^{(29)}$.

\section{Resultados}

Os 12 estudos incluidos na revisão para análise foram feitos entre os anos de 2004 e 2017. Com relação ao país de origem de publicação concentraram-se nos Estados Unidos da América e no Canadá. 
O quadro 04 descreve a distribuição das publicações quanto ao tipo de relato e metodologia.

Quadro 04. Distribuição das publicações quanto ao tipo de relato e metodologia - São Paulo, SP, Brasil, 2018.

\begin{tabular}{|l|l|l|}
\hline $\begin{array}{l}\text { Tipo de relato e } \\
\text { metodologia }\end{array}$ & Quantitativo & Porcentagem \\
\hline $\begin{array}{l}\text { Estudo Empírico - } \\
\text { delineamento qualitativo }\end{array}$ & 05 estudos & $41,66 \%$ \\
\hline $\begin{array}{l}\text { Estudo Empírico - } \\
\text { delineamento } \\
\text { quantitativo }\end{array}$ & 02 estudos & $16,66 \%$ \\
\hline $\begin{array}{l}\text { Estudo empírico - } \\
\text { delineamento misto }\end{array}$ & 03 estudos & $25 \%$ \\
\hline $\begin{array}{l}\text { Teórico - delineamento } \\
\text { de revisão }\end{array}$ & 02 estudos & $16,66 \%$ \\
\hline
\end{tabular}

Nota: $(\mathrm{N}=12)$

\subsection{Categorias de Análise}

Após leitura integral dos trabalhos incluídos na presente revisão, os pontos essenciais foram analisados e reconhecidos em categorias de análise que conceberam a síntese narrativa dos achados.

O quadro 05 retrata os quantitativos de estudos de acordo com cada categoria de análise. Vale destacar que os estudos foram enquadrados em mais de uma categoria de análise quando identificado.

Quadro 05. Barreiras de acesso relacionadas as mulheres - São Paulo, SP, Brasil, 2018.

\begin{tabular}{|l|l|l|l|}
\hline Categorias & EstudoEmpírico & EstudoTeórico & Total \\
\hline Barreiras & 09 estudos & 03 estudos & 12 estudos \\
Internas: & & & \\
Construção & & & \\
\hline
\end{tabular}




\begin{tabular}{|c|c|c|c|}
\hline $\begin{array}{l}\text { Social do gênero } \\
\text { feminino } \\
\text { Estigma social }\end{array}$ & & & \\
\hline $\begin{array}{l}\text { Barreias } \\
\text { Externas: } \\
\text { Determinantes } \\
\text { sociais }\end{array}$ & 11 estudos & 01 estudo & 12 estudos \\
\hline
\end{tabular}

Nota: $(\mathrm{N}=12)$

\subsubsection{Barreiras de Acesso}

$\mathrm{Na}$ literatura encontramos estudos que apontam que as mulheres tem problemas mais graves ao entrarem em um serviço em busca de tratamento para álcool e outras drogas; além de obstáculos que impedem o acesso e à aderência ao tratamento se comparar com a população masculina (61).

Mesmo com as diferenças culturais e geográficas do mundo, as mulheres vivenciam muitas das mesmas barreiras ao acesso e permanência no tratamento. Essas barreiras têm que ser mais freqüentes com suas responsabilidades como esposas ou parceiras e mães, as dificuldades associadas a ter um parceiro sexual que usa substâncias e o significativo estigma adicional associado aos problemas de uso de substâncias por mulheres (61).

Podemos categorizas essas barreiras em: internas, externas e estruturais ${ }^{(61,62)}$.

Barreiras internas que se caracterizam como obstáculos no acesso à busca do tratamento se consistem em: negação da severidade do problema com o álcool e outras drogas; medo do estigma social relacionado ao consumo de SPA; preocupação em perder os filhos; culpa e vergonha (62).

Barreiras externas que se caracterizam como obstáculos encontrados por mulheres são associados à interpessoalidade, como dificuldade de apoio de familiares e amigos; determinantes sociais; entre outros ${ }^{(62)}$.

Barreiras estruturais se caracterizam pelo baixo conhecimento da equipe de saúde em identificar demandas recorrentes do uso do álcool e outras drogas; falta de serviços de tratamento que auxilie as mulheres no cuidado com seus 
filhos; falta de recursos financeiros e econômicos e cobertura de seguros de saúde (62).

\subsubsection{Barreiras Internas: Construção social do gênero feminino e Estigma Social}

Nesta categoria temática os 12 estudos identificados trataram por analisar as barreiras internas; sendo seis estudos que relatam quanto a questão do gênero feminino em nossa sociedade contemporânea e seis estudos que analisaram quanto ao estigma social.

Uma questão importante de análise está relacionada as violências psicológicas e físicas sofridas pelas mulheres. Os abusos sofridos ao longo da vida que impulsionaram as mulheres ao uso e a negação de acesso aos serviços de saúde (31).

Dois estudos apresentam programas específicos para mulheres gestantes que fazem uso de SPA ou que enfrentam a dependência de tais substâncias ${ }^{(32-33)}$.

Um dos estudos empíricos relatou a importância de assistência em obstetrícia e álcool e outras drogas. Também descreveu como uma barreira importante de acesso a ser considerada o "dever moral" da mulher gestante. $O$ mesmo estudo também fez uma associação do medo das mulheres relatarem que são dependentes de alguma substância e serem encaminhadas ao sistema criminal devido a legislação de 18 estados americanos, penalizando a mulher sob o estatuto de abuso infantil (32). O estudo enfoca mulheres que são dependentes de opióides. Podemos associá-lo a outro estudo que faz uma análise quanto as diferenças de gênero relacionada ao uso de substância psicoativa (SPA), ressaltando que mulheres fazem uso abusivo de opióides e medicamentos psicotrópicos, mesmo sem receita médica ${ }^{(34)}$.

Por sua vez, em um estudo acerca de mulheres gestantes e uso de SPA, converge novamente em discursos sociais de controle e moralização da gravidez, além da desaprovação da sociedade com relação a tal temática (33).

Outro estudo (35) afirma que, historicamente as mulheres enfretam muitas barreiras de acesso aos serviços de saúde mental e/ou álcool e outras drogas. Apontou como uma barreira de acesso importante o medo de perder a custódia 
dos seus filhos; ressaltando tal conceito como uma barreira específica do gênero feminino a responabilidade do cuidado para com o filho. Corrobora com o estudo (36).

Um dos estudos ${ }^{(37)}$ relatou quanto a dificuldade de acesso das mulheres o papel da mulher e seus comportamentos associados a subcultura do meio em que está inserida; além das diferenças de gênero ao se tratar de uma patologia como a dependência de SPA.

Por fim, também acerca da criminalização da mulher em relação ao uso de SPA, um estudo destaca que o tratamento de álcool e outras drogas deve considerar as questões específicas de gênero, promovendo um cuidado individualizado e atentando-se as necessidades específicas singularmente ${ }^{(31)}$.

Quanto aos estudos que compuseram acerca do estigma social relataram de tal temática na procura das mulheres por serviços e o medo de permanecer em acompanhamento.

Podemos aqui também problematizar quanto aos serviços que preconizam a abstinência como uma modalidade de cuidado. Não compreender as outras modalidades de cuidado em álcool e outras drogas constitui-se como estigma enfrentado em questão ao acompanhamento do tratamento (33).

Um estudo empírico relatou quanto a dificuldade de acesso as mulheres e o agravamento de tal dificuldade para as que se encontravam em situação de rua. Destacou que uma das barreiras de acesso ou a falta de vontade das mulheres em acessar serviço estava diretamente ligada ao estigma do uso na vertente do gênero feminino ${ }^{(38)}$.

Outro estudo empírico afirmou que existem poucos trabalhos que avaliem as questões de acesso a serviços relacionados a mulheres de baixa renda. Destacou também que o estigma da comunidade em que a mulher está inserida se constrói como uma barreira de cuidado e que quando associado ao uso a mesma apresenta comorbidades psiquiátricas, o estigma é ainda maior (35).

Os dois trabalhos descritos acima convergem ainda para uma estratégia de cuidado a elaboração de ambientes que incentivem a mulher a buscar auxílio, além do serviço ser receptivo, compreensível e não crítico. 
Um estudo de revisão destacou quanto ao estigma da mulher, no sistema criminal, associado ao uso de SPA. Refere que nesse caso o indivíduo sofre por dois estigmas impostos socialmente - condenação e uso de drogas (31).

Outro estudo empírico ressalta quanto ao estigma social sofrido por mulheres carentes, afro-americanas inseridos emuma comunidade que necessita de auxílio quanto a dependência de drogas. Assim, foi o único estudo que ressaltou a influência das religiões na não procura por cuidado (39).

Por fim, corroborando com o estudo descrito acima com relação a minorias, um estudo relatou quanto as necessidades de cuidado em álcool e outras drogas de mulheres refugiadas. Além de todas as barreiras sociais enfrentadas por elas, o estigma social da dependência de drogas afeta significativamente a busca por serviços e ressalta a importância de programas visando a promoção à saúde em nível comunitário ${ }^{(40)}$.

\subsubsection{Barreiras Externas: Determinantes sociais}

Também, os 12 estudos aqui incluídos na presente categoria de análise tratou dos determinantes sociais como barreira de acesso ao tratamento para mulheres.

Especificamente os determinantes sociais que se constituem como barreira de acesso estão vinculados à raça, baixa renda, falta de moradia, ausência de seguro médico, não ter acesso à educação e não ter auxílio dos filhos para que possam realizar o cuidado em saúde ${ }^{(40)}$.

Um estudo empírico promoveu uma reflexão acerca do cuidado em saúde de populações minoritárias. Afirmou que as desigualdades sociais se transformam em determinantes no momento que o indivíduo busca e acessa serviços em álcool e outras drogas ${ }^{(37)}$.

O mesmo estudo distingue as barreiras de acesso em individuais e ambientais. Barreiras de acesso individuais são: renda, motivação ao cuidado, meio sócio-cultural inserido por exemplo e barreiras de acesso ambientais são: estrutura do sistema de cuidado em saúde, transporte, possibilidades de cuidados infantis etc ${ }^{(37)}$. 
Por fim, outro estudo aponta que para que o cuidado seja efetivo os profissionais devem se atentar aos focos primitivos ao uso de SPA que são: pobreza, discriminação e isolamento social (33).

\section{Discussão}

Realizar o mapeamento da literatura que trata do acesso das mulheres em serviços comunitários de saúde mental, especificamente as barreiras que influenciam o acesso, possibilitou explorar as necessidades de cuidado e as adversidades que os pesquisadores e profissionais enfrentam na área.

A maioria dos estudos incluídos promoveu uma reflexão acerca dos determinantes sociais que se constituem como uma barreira de acesso às mulheres na busca por serviços de saúde mental em álcool e outras drogas.

Entretando, pesquisas e estudos que nos auxiliam na identificação dessas barreiras de acesso e como fazer para derrubá-las ainda são pouco exploradas diante da complexidade do tema em questão.

É revelado na literatura científica que o início precoce do uso de SPA em mulheres é uma realidade, acarretado por diversas influências tais como pressão de grupos sociais, fuga de problemas e traumas, violência doméstica, busca de alternativas de vida, aprendizado social, interação familiar, traços de personalidade e fatores genéticos ${ }^{(8)}$.

A importância do tema é validada por dados que comprovam o aumento do consumo de SPA em mulheres, que estão se aproximando do padrão de consumo masculino. Embora que o consumo ainda seja menor, mulheres adoecem mais cedo e de forma mais grave do que os homens ${ }^{(8)}$.

$\mathrm{Na}$ literatura foi encontrado que os homens e as mulheres diferem-se com relação a impulsividade para o uso de SPA e cognição. A relação da impulsividade e busca pelo álcool enlaça fatores comportamentais, cognitivos e hereditários. Podemos perceber a diferença sendo menor a tolerância ao álcool nas mulheres, embora iniciam o consumo de álcool mais tarde e em menores quantidades; entretanto, os homens permanecem sendo os maiores consumidores ${ }^{(63)}$.

Outros estudos mostraram que as mulheres são vulneráveis em aspectos comportamentais e cognitivos, além dos aspectos biológicos, em 
resposta ao consumo do álcool, embora apresentem menor prédisposição ao uso (63).

Uma das categorias de análise foi decorrente das Barreiras Internas construção social do gênero feminino. É um fato a relação entre o consumo de SPA e os elementos envolvidos na temática. Diversos fatores intrinsecos e extrinsicos permeiam o uso de SPA ${ }^{(8)}$.

A demanda de gênero encontra-se no eixo das relações de poder entre as pessoas, sejam profissionais, sejam familiares como usuários dos serviços de saúde. Gênero aqui tratado não representa apenas a diferença entre os sexos, em termos biológicos, mas sim as relações de poder entre os diversos níveis sociais ${ }^{(43)}$.

Considera-se gênero "um sistema de signos e símbolos que denota relações de poder e hierarquia entre os sexos e modos diferentes de expressão no interior de relações do mesmo sexo", portanto, "algo relacional e transversal, interativo com classe social, raça, diferenças de geração, cultura, e não uma condição que determina, por si só, diferenciais de vulnerabilidade" ${ }^{44)}$ (p.695).

Gênero, segundo Scott é um elemento constitutivo das relações sociais baseadas nas diferenças entre os sexos; é uma forma primária de relações significantes de poder; um campo primário dentro do qualou por meio do qual se articula o poder; facilita um modo de decodificar o significado e de compreender as complexas conexões entre várias formas de interação humana ${ }^{(43)}$.

O termo gênero tornou-se alvo e foco de ações feministas. Desde então, o olhar mais cuidadoso ao gênero resultou na ampliação para o campo das políticas e programas a fim de proporcionar maior igualdade entre homens e mulheres ${ }^{(45)}$.

As evidências encontradas nesta revisão convergem com a construção social do gênero feminino traduzindo culturalmente o papel social de ser mulher. Cada mulher traz consigo valores sociais predominantes, impostos culturamente como: passividade, submissão, única responsável pelo cuidado para com os filhos, entre outros ${ }^{(46)}$.

O gênero é responsável por transformar as pessoas em sujeitos sociais, permeados pela relação de poder e dominação. A mulher é considerada, historicamente, como ser submisso ao homem, originando o machismo e suas crenças que, cotidianamente, se enraízam em valores distorcidos para 
manutenção de comportamentos da sociedade que infringem os direitos da mulher (46).

Com muita facilidade ao nos atentarmos aos detalhes de nossa sociedade percebemos a diferença entre o ser homem e o ser mulher. Em serviços de apoio psicossocial, por exemplo, o índice de adesão aotratamento pelos homens é maior em comparação com as mulheres. Leis precisam ser implantadas para a compreensão da igualdade de gênero, mulheres vítimas de violência mostram medo em maior escala às violações sexuais do que os homens e, assim por diante ${ }^{(43)}$.

De acordo com artigo que discorre sobre machismo, encontramos tal passagem para clarificar o entendimento sobre o conceito central, leitura contemporânea em seu tema, mesmo sendo realizada há quase 40 anos. 0 machismo é definido como um sistema de representações simbólicas que mistifica as relações de exploração, de dominação, de sujeição entre o homem e a mulher (47).

As mulheres são alvos de injustiças sociais de diferentes ordens ao longo da história ${ }^{(43)}$. Sendo assim, violência baseada no gênero se constitui como um fenômeno social que impacta diretamente na maneira de viver, adoecer e morrer das mulheres ${ }^{(44)}$.

Então, a relação de poder e gênero é expressa na relação de dominação e exploração, constituida socialmente, influenciada e impacta em diferentes épocas e comunidades. Essa relação submete a mulher a diferentes formas de adoecer, sem sua real necessidade sendo amparada ${ }^{(45)}$.

Essas desigualdades sociais que permeam o gênero, estabelecem-se nos diferentes aspectos da vida, qualificando em um certo privilégio dos homens perante as mulheres. Sendo assim, ao analisar as desigualdades frente a especificidade do gênero é possivel identificar esteriótipos e as relações de poder existentes entre essa associação ${ }^{(45)}$.

Tais esteriótipos e conjecturas são mantidos por homens ao longo da existência e internalizados nas mulheres, acarretando na produção de desvantagens em todos os âmbitos sociais ${ }^{(45)}$.

Ainda que os homens apresentem taxas de consumo de SPA maior do que as mulheres ao longo da vida, atualmente encontramos na literatura uma possivel equiparação das taxas de consumo entre homens e mulheres. Podemos 
evidenciar tal apontamento na relação direta com as mudanças sociais, culturais, educacionais e políticas que seguem em nosso século, na vida das mulheres ${ }^{(45)}$.

O uso de SPA, principalmente ilícitas, por mulheres vai de encontro com a incompatibilidade dos papéis sociais e culturais determinados a elas? Seria então uma consequência de tal concepção um encobrimento do uso (de álcool e ouras drogas) em mulheres, agravando o adoecimento das mesmas e as expondo a uma maior vulnerabilidade ${ }^{(45)}$ ?

Dois estudos empíricos propuseram analisar programas de saúde gestacional em mulheres dependentes de SPA (31-33). O que foi encontrado no discurso converge para o sentimento gerado de ameaça de perda de poder familiar. Assim, o papel social destinado as mulheres, principalmente a função maternal torna-se evidente e passível de discussão.

Ainda com relação a esses estudos, a SPA mais utilizada e relatada pelas mulheres foi deopióides sem receita médica. Logo, pode-se associar a outro estudo que confirma tal achado (34); consistindo novamente em uma discussão do papel social da mulher sob a ótica do gênero (16):

[...] Já o Diazepam é um medicamento que permite as mulheres continuarem cumprindo seu papel social: ser cuidadora dos filhos, do lar, aceitar a subjugação social e sexual de seus parceiros etc. Enfim, há uma perversidade no sistema, na qual as relações de gênero são tornadas invisíveis [...] (p.315).

Encontramos na literatura diversos fatores que justificam o início e a manutenção do uso de SPA em homens e mulheres. Então, para as mulheres, tais fatores estão associados às experiências traumáticas vivenciadas, comorbidades psiquiátricas e ter familiares e/ou companheiros (as) usuários. Tais fatores são diferentes entre os gêneros ${ }^{(45)}$.

Independentemente dos papéis pré-determinados socialmente e culturalmente as mulheres faz-se necessário uma elaboração e compreensão dos diferentes sentidos designados ao uso de SPA a fim de garantir que não haja barreiras direcioanadas ao acesso vinculadas ao gênero (45).

Vale ressaltar que a barreira de acesso em serviço, independente de qual seja, define-se como uma violência à mulher, uma violação de direitos. $O$ meio social em que ela está inserida constitui-se também como barreira de 
acesso; uma vez que além dos papeis sociais determinados, há regras informais e costumes locais a serem considerados.

A associação entre mulheres e o uso de SPA não é uma categoria de análise homogênea, uma vez que há diversas singularidades que independem do sujeito em questão. Continuamente, as barreiras de acesso ao serviço e manutenção do tratamento também são heterogênas, representando os comportamentos e papeis pré-determinados socialmente às mulheres ${ }^{(45)}$.

O estigma social - Barreira Interna enfrentado pelas mulheres na busca de acesso aos serviços de álcool e outras drogas simbolizou outra categoria de análise e que está intimamente ligada a construção social do gênero feminino.

As pessoas em uso de SPA devido ao comprometimento social impactado em suas vidas acabam por terem laços de relacionamentos rompidos, como consequência o isolamento social e conflitos nas esferas da vida. Tais rupturas favorecem para a construção do preconceito e estigma em relação aos usuários ${ }^{(55)}$.

Desta forma, o conceito de preconceito utlizado aqui dá-se por um julgamento antecipado e precoce acerca da temática do álcool e outras drogas. O preconceito é a valoração negativa que se atribui às características da alteridade; implica a negação do outro diferente e, no mesmo movimento, a afirmação da própria identidade como superior/dominante usuários ${ }^{(55)}$.

Por sua vez, estigma enfatiza uma atitude de prejulgamento, como sinal infamante, indigno e desonroso, uma mancha na reputação de alguém, e que pressupõe a contaminação, o contágio, a transmissão, tornando urgente e necessário o isolamento do agente contaminador usuários ${ }^{(55)}$.

Como uma definição de estigma proposta em 1963 podemos refletir acerca da definição de uma marca ou um sinal que designaria ao seu portador um status "deteriorado" e, portanto, menos valorizado que as pessoas "normais", chegando ao ponto de incapacitá-lo para uma plena aceitação social de usuários (56).

Entretanto, tal conceito vem sofrendo modificações ao longo dos anos, a fim também de permear as questões psicossociais. Logo, o estigma pode ser entendido como um processo dinâmico, que é elaborado socialmente, ajustado por forças históricas e sociais, moderado por efeitos imediatos do contexto social 
e situacional sobre a perspectiva do estigmatizador, estigmatizado e da interação entre os dois usuários ${ }^{(57)}$.

O estigma direcionado as questões de saúde mental, álcool e outras drogas tem influência diretamente no modo da sociedade se relacionar, uma vez que estão associados a comportamentos marginais e criminais. Dessa forma, a exclusão social e a violência direcionada a essas pessoas são tamanhas (55).

A utilização de abordagens e estratégias não terapêuticas à essa população é reconhecida na literatura. Tal apontamento é reflexo das relações de poder que permeiam a construção social, rotulando e estereotipando tais sujeitos com os níveis mais degradantes da hierarquia de produção ${ }^{(55)}$.

Uma temática que promove uma discussão mais aprofundada com relação ao estigma dá-se pelo capitalismo. $\mathrm{O}$ capitalismo determina à sociedade quais produtos e mercadorias poderão serem consumidas e quais deverão serem adquiridas de forma ilícita, inclusive as SPA. A construção social acerca da temática das drogas estabelece padrões morais com relação ao modo singular de interação do sujeito com as esferas da vida; implicando assim em um estigma à população de enfoque nesta revisão (55).

Os meios de produção social e as relações baseadas em hierarquia e poder caracterizou os usuários de SPA como marginais e criminosos. Essa caracterização atribui significado errôneo a tal população, que consequentemente os internaliza, gerando exclusão social e produzindo marcas decisivas singulares em cada sujeito ${ }^{(55)}$.

O estigma é capaz de produzir consequências na pessoa que sofre, de maneira singular, em todas as esferas da vida. É relatado na literatura que é um fator que reduz significativamente na probabilidade de busca de ajuda (57).

O estigma inserido nas pessoas que sofrem por transtornos mentais e que fazem uso de álcool e outras drogas é reproduzido socialmente, incluindo os profissionais de saúde que estão para atender e acolher tal demanda. Dessa forma, uma reflexão acerca de estratégias a fim de superar tal barreira de cuidado deve ser realizada ${ }^{(57)}$.

Sendo assim, ressaltar que o consumo de SPA não é uma condição moral e criminal, mas está intimamente ligada aos determinates sociais, psicológicos e biológicos individuais. 
Em outras palavras, os diversos setores sociais são também responsáveis na superação do estigma em sujeitos com a problemática do álcool e outras drogas. Deve também proporcionar a garantia de direitos e deveres de cada sujeito como um cidadão civil, desmistificando tal demanda (55).

O consumo de álcool e outras drogas em mulheres ainda é pouco estudado no Brasil (47). Está claro na literatura que há uma heterogeneidade social e cultural das pessoas que fazem uso de SPA. Porém, muitas vezes nos deparamos com o mesmo enfoque de assistência e cuidado (44). Dessa forma, as mulheres são distintas desse enfoque, no qual precisam de apoio diferencial, relativo às necessidades específicas de gênero.

Cada mulher enfrenta a condição do uso de SPA ou dependência química demaneira singular. Vale ressaltar tal apontamento a fim de não transformar um único elemento de análise como principal enfoqueassistencial entre as mulheres ${ }^{(44)}$.

O estigma em relação ao uso, as diferentes estratégias que as mulheres atuam em sua proteção em diferentes situações reforçam a marca da divisão social de classes e o poder masculino ${ }^{(44)}$.

A fim de lidar com o estigma é importante utilizar da perspectiva de gênero como uma abordagem estratégica; compreendida por meio de símbolos e signos nas relações de poder presentes nas interações humanas (46).

Associando o estigma às mulheres, com base nas desigualdades de gênero é sábido afirmar que ele existe e permeia o processo de enfrentamento e de mudanças no papel social feminino. Estratégias de acolhimento frente aos contextos morais impostos devem ser quebrados a fim de garantir o acesso à essa população em espaços de atenção ${ }^{(8)}$.

Como mecanismos de cuidado à essa população destacam-se a disponibilidade integral dos serviços comunitários, acolhimento sem moralidade dos profissionais, programas específicos para o gênero feminino e capacitação técnica da equipe multiprofissional ao lidar com necessidades complexas ${ }^{(8)}$.

Os fatores que foram identificados nos estudos como estigmatizantes às mulheres com relação ao acesso em serviços de saúde mental álcool e outras drogas foram: trajetória de vida permeada de violência física e psicológica, raça, baixa renda, religião e mulheres em conflito com a lei no sistema penitenciário (31-33-35-37-38-39-40-41-42). 
Assim, é necessário refletir acerca das categorias aqui apontadas que permeiam o acesso das mulheres em serviços comunitários de saúde mental em álcool e outras drogas. Não é possível discorrer acerca da temática sem a associação de tais categorias, uma vez que estão intimamente relacionadas.

A influência dos determinantes sociais - Barreira externa foi o tema mais frequente entre os estudos (Quadro 05). Nos últimos anos nos deparamos na literatura com estudos que associam aspectos econômicos, sociais, ambientais com a saúde. Um tanto diferentes dos séculos passados em que 0 foco dos estudos de saúde era exclusivamente biológico (48).

O conhecimento da influência dos determinantes sociais no processo de saúde doença são importantes uma vez que permitem a reflexão das estratégias de intervenções possíveis e efetivas no planejamento de cuidado em saúde ${ }^{(49)}$.

Uma referência de cuidado em saúde voltada para a promoção de saúde presume que o processo saúde-doença é produto dos determinates sociais, econômicos, culturais, étnicos, raciais, psicológicos e comportamentais. Sendo assim, constituem-se como fatores de risco para o adoecimento populacional, impactando fortemente na qualidade de vida (50).

A OMS (51) desempenha uma concepção holística acerca dos determinantes sociais em saúde. Compreende que a desigualdade na saúde da maioria mais carente é produto da distribuição desigual de poder, rendimento, bens e serviços em âmbito mundial.

Assim, o acesso a serviços de saúde, escola, atividades de recreação, moradia e demais fatores relacionados à qualidade de vida faz parte da lógica de desigualdades. É ainda resultante da associação de políticas socias minoritárias de baixa qualidade e estruturas econômicas desiguais. Por fim, os determinantes estruturais e de condições de vida fazema parte dos determinantes sociais de saúde, responsabilizando as desigualdades de saúde dentro dos países e na relação entre eles (51).

As diferenças de saúde não podem ser resumidas exclusivamente à uma análise biológica, uma vez que tais diferenças são resultantes de hábitos e comportamentos concebidos socialmente, além da contribuição de fatores que não podem ser corrigidos individualmente ${ }^{(48)}$.

Por certo a má distribuição dos cuidados de saúde - não prestando cuidados aos mais necessitados - é um dos determinantes sociais da saúde. A 
OMS define então que os determinantes sociais de saúde são as condições nas quais as pessoas vivem e trabalham ${ }^{(49)}$.

A concepção de determinantes sociais que é utilizada nessa revisão consiste em "fatores sociais, econômicos, culturais, étnicos/raciais, psicológicos e comportamentais que influenciam a ocorrência de problemas de saúde e fatores de risco na população" (52).

O processo do capitalismo resultou para a sociedade o agravamento da desigualdade social e ampliou a produção de bens e riqueza também de forma desigual. Logo, o processo do capitalismo influencia diretamente na produção de saúde ${ }^{(48)}$. Dessa forma, as desigualdades sociais entre as diferentes classes econômicasrepresentam o enfoque do processo de saúde-doença.

Os principais meios que influenciam a desigualdade em saúde são: diferenças de renda que possibilitam ou não o acesso aos recursos de saúde; os aspectos psicossocias que são singulares, partindo das experiências vivenciadas individualmente e as relações entre a saúde e o meio social em que o sujeito está inserido ${ }^{(48)}$.

Existem diversos modelos que buscam explicar a interação da saúde e os determinantes sociais. Em um estudo ${ }^{(53)}$ estabeleceu sete princípios para o desenvolvimento das diferenças em saúde: variação biológica; a utilização de hábitos, costumes e práticas saudáveis; o fato de certos grupos perceberem e utilizarem primeiro alguns hábitos considerados saudáveis; a utilização de hábitos e comportamentos prejudiciais à saúde devido à restrição de alternativas; exposição a riscos no ambiente de trabalho; acesso inadequado aos serviços essenciais de saúde e a outros serviços públicos e; a tendência dos problemas de saúde causarem efeitos mais severos nos indivíduos de classes sociais desfavorecidas.

Conforme analisado nos estudos que identificaram os determinantes sociais como barreira do acesso de mulheres a serviços de saúde mental em álcool e outras temos, raça, baixa renda, falta de moradia, ausência de seguro médico, não ter acesso à educação e não ter auxílio com os filhos para que possam realizar o cuidado em saúde.

Um estudo empírico relatou um programa específico para mulheres afroamericanas inserido na comunidade. O mesmo destacou que após 06 meses do inicio das ações, as mulheres conseguiram se organizar quanto a ter um 
domicílio e um emprego, favorecendo a continuidade do tratamento e a queda das taxas de uso de SPA relatadas ${ }^{(37)}$.

Para que as barreiras de acesso a serviços relacionadas aos determinates sociais em saúde possam ser superadas, é necessária uma reflexão e articulação entre os diversos setores políticos, econômicos, educacionais com a finalidade de garantir a promoção da saúde ${ }^{(48)}$.

Diante do exposto até o momento, fica claro que as características sociais e econômicas impactam nas condições de vida e de trabalho heterogêneos. E que então, os comportamentos e modos de viver das pessoas são influenciados por tais fatores ${ }^{(49)}$.

Também é possível afirmar que as circunstâncias do meio social refletem desigualdades relacionadas as vulnerabilidade e exposições acometem a saúde das pessoas e representam fatores de risco para o adoecimento ${ }^{(49)}$.

A visto disso é ainda mais agravante a situação para mulheres. Além das barreiras associadas aos determinantes sociais, barreiras de gênero são somadas as dificuldades do acesso em saúde, particularmente em álcool e outras drogas. Fatores como o estigma, que também se formou em categoria de análise e a construção do gênero fortalecem o processo de adoecimento aqui descrito.

No Brasil a Lei 8080/90 afirma que a saúde tem fatores fundamentais e condicionantes como alimentação, a moradia, o saneamento básico, o meio ambiente, o trabalho, a renda, dentre outros que refletem a organização social e econômica do Brasil (49).

Ao nos depararmos com situações de vulnerabilidade social e analisarmos a população feminina em situação de rua percebemos dados que convergem para a temática em discussão. Mulheres em situação de rua são acometidas por diversas esferas sociais que se constituem como agravantes em sua saúde como: violência sexual; laços familiares rompidos; dificuldade econômica; entre outros ${ }^{(64)}$.

Um estudo realizado em Belo Horizonte ${ }^{(64)}$ mostra que os motivos que levam as mulheres a vivenciar a situação de rua são: problemas familiares, sendo eles o uso abusivo de álcool, desavenças e sofrimento mental e; questões econômicas. Além de relatos que expressaram desentendimentos, brigas e agressões na família. 
O estar em situação de rua propicia o consumo de álcool e outras drogas. Vivenciar o contexto da rua se torna um fator de vulnerabilidade para 0 uso de SPA, que por sua vez, torna-se um apoio a fim de lidar com as questões do viver na rua ${ }^{(64)}$.

É possível observar que mulheres possuem poucos recursos de defesa ao vivenviar a situação de rua. Logo enfretam situações nos quais não possuem nenhum ou pouco recurso na constituição de um espaço físico de proteção ${ }^{(64)}$.

O consumo de SPA pode ser um determinante de entrada e permanência da situação de rua; logo no adoecimento de vínculos e relações saudáveis das mulheres ${ }^{(64)}$.

Em outras palavras, os determinantes biológicos representam uma diferença pequena comparado aos sociais no processo de saúde-doença ${ }^{(48)}$. Assim, tal processo deve ser considerado como bio-psico-social. Considerando isso, para que haja superação dessas barreiras é necessária uma resolutibilidade de diversas questões sociais; uma vez que as condições dos estilos e hábitos de vida estão condicionadas aos determinantes socias.

A influência dos determinantes sociais no processo saúde-doença reflete em políticas voltadas às populações pouco representadas, a fim de não desperdiçar recursos e promover a ineficácia nas estratégias de prevenção, promoção e assistência à saúde ${ }^{(48)}$.

Identifica-se então que os agravos da pobreza à saúde representam um objeto de análise acerca do tema. Deve haver promoção de condições de desenvolvimento técnico científico diante de um processo saúde-doença e determinantes socias impostos. A saúde relaciona-se diretamente no modo como a sociedade está organizada; assim a saúde se configura em uma condição socialmente imposta ${ }^{(48)}$.

\section{Considerações Finais}

A presente revisão de escopo permitiu mapear que o conhecimento acerca do acesso das mulheres em serviços comunitários de saúde mental em álcool e outras drogas é relativamente pouco estudado.

Com a realização desta revisão, as barreiras de acesso às mulheres aos serviços de saúde mental álcool e outras drogas foram mapeadas: demandas 
específicas do gênero, estigma social e a influência dos determinantes sociais no processo de cuidado em saúde.

A discussão do gênero, principalmente acerca das desigualdades entre os gêneros foram utilizadas como referencial teórico. A sociedade capitalista na qual estamos inseridos produz a internalização de papéis sociais competentes a cada gênero. Esse fator produz uma diferenciação no momento de busca de cuidado e acesso à saúde, impactante de forma desigual entre homens e mulheres.

Nessa categoria de análise foi possível identificar os principais achados: o cuidado em saúde às mulheres gestantes em uso de SPA e o sentimento de ameaça do poder familiar. Os estudos permitiram uma reflexão acerca das funções sociais designadas às mulheres e o quanto as mesmas produzem dificuldade de acesso ao cuidado em saúde mental.

Os determinates sociais que são frutos da sociedade capitalista também foram identificados como barreira de acesso às mulheres em grande parte dos estudos incluídos. Entre eles, foram destacados: a vulnerabilidade das mulheres em situação de rua, situação de imigrantes refugiadas, baixa renda e ambiente social.

Foi possível destacar que os determinantes em saúde não podem ser considerados meramente biológicos; uma vez que os determinantes sociais influenciam e impactam diretamente o cuidado em saúde.

Por sua vez, o estigma foi identificado como categoria de análise. Os fatores constatados ao estigma foram: mulheres sofrerem violência física e psicológica durante sua trajetória de vida, raça/etnia "diferente", possuirem baixa renda, serem egressas do sistema penitenciário e ser de uma religião "diferente".

Dessa forma, tais fatores dificultam o cuidado em saúde de mulheres, traduzidos em barreira de acesso ao cuidado em saúde mental.

É válido o destaque para que os estudos encontrados retratam outro modelo de saúde, em outros países - especificamente Estados Unidos e no Canadá. No Brasil, com a lei que regulamenta o SUS a disponibilidade de acesso mostra-se um tanto diferente. Dessa forma, uma reflexão mais aprofundada com relação à temática se faz necessária. 
As mulheres não encontram facilidades para acessar serviços e quando conseguem acessá-los, desacreditam dos mesmos. É possível afirmar tal condição uma vez que os achados aqui identificados corroboram tal condição.

As mulheres necessitam de ações voltadas para seu cuidado permeadas pelas condições específicas do gênero. Discussões acerca do papel da mulher pré-determinado em nossa sociedade, violência de gênero, função maternal, traumas físicos e psicológicos devem refletir no acolhimento integral nos serviços.

Planejamento de ações singulares e promoção de discussão em âmbito nacional e internacional são essenciais em meio a sociedade capitalista em que estamos inseridos. Devido ao avanço das mulheres na sociedade, políticas voltadas a tal população devem serem repensadas e planejadas; a fim de lidar com a demanda do aumento da prevalência de mulheres usuárias de SPA.

Como lacuna de pesquisa a carência de estudos associados à temática; uma vez que dos estudos iniciais potencialmente elegíveis ( $n=601)$ apenas 12 corresponderam a pergunta de pesquisa e critérios de inclusão aqui determinados.

Além da identificação das categorias temáticas apresentadas, alguns estudos contribuíram com necessidade de atenção no qual os serviços comunitários de saúde mental em álcool e outras drogas devem possuir. Assim, destacam-se: acolhimento das equipes de saúde visando a garantia da singularidade da mulher; integração da assistência em saúde e saúde mental; capacitação das equipes de saúde; abordagem às mulheres não crítica; criação e manutenção de um ambiente de cuidado que incentive a mulher ao acompanhamento; garantiada promoção da saúde em nível comunitário; avaliação das necessidades reais das mulheres e promoção da segurança e a confiança das mulheres em seu cuidado.

Por fim, este estudo contribuirá para uma assistência de enfermagem que alcance o cuidado psicossocial, comprometido com as necessidades das mulheres, refletindo e corroborando com as diferenças de gênero. Auxiliará para uma melhor preparação no momento do acolhimento da demanda específica das mulheres, priorizando as necessidades singulares do gênero. 


\section{Referências}

1. Barroso SM, Silva MA. Reforma Psiquiátrica Brasileira: A caminho da desinstitucionalização pelo olhar da historiografia. Revista da SPAGESP. 2011; 12 (1): 66-78.

2. Brasil. Ministério da Saúde. Reforma Psiquiátrica e a política de saúde mental no Brasil. Conferência Regional de Reformas dos Serviços de Saúde Mental: 15 anos depois de Caracas. Brasília (DF); 2005.

3. Berlinck MT, MagtazAC, Teixeira M. A Reforma Psiquiátrica Brasileira: perspectivas e problemas. Rev. Latinoam. 2008; 11(1): 21-27.

4. Gama JRA. A reforma psiquiátrica e seus críticos: considerações sobre a noção de doença mental e seus efeitos assistenciais. Revista de Saúde Coletiva. 2012; 22 (4): 1397-1417.

5. Carlini EA, Galduróz JCF, Noto AR, Fonseca AM,Carlini CM, Oliveira LG, Nappo AS, Moura YG, Sanchez ZVDM. II Levantamento Domiciliar sobre - Uso de Drogas Psicotrópicas no Brasil: estudo envolvendo as 108 maiores cidades do país - 2005. São Paulo: Centro Brasileiro de Informações sobre Drogas Psicotrópicas (CEBRID); Universidade Federal de São Paulo; 2005.

6. Brasil. Secretaria de Políticas para as mulheres. Plano Nacional de Políticas para as mulheres (2013-2015) [Internet]. Brasilia: SPM; 2013.

7. Presidência da República (BR). Secretaria Nacional de Políticas sobre Drogas. Legislação e Políticas Públicas sobre Drogas. Brasilia: SENAD; 2010.

8. Albuquerque CS, Nóbrega MPSS. Barreiras e facilidades encontradas por mulheres usuárias de substância psicoativas na busca por tratamento especializado. SMAD. 2016; 12 (1):22-29.

9. Brasil. Ministério da Saúde. A Política do Ministério da Saúde para a Atenção Integral a Usuários de Álcool e Outras Drogas. In: Brasil. Ministério da Saúde. Brasília; 2003.

10. Brasil. Ministério da Saúde. Portaria no 3.088 , de 23 de dezembro de 2011. Institui a Rede de Atenção Psicossocial para pessoas com sofrimento ou transtorno mental e com necessidades decorrentes do uso de crack, álcool e outras drogas, no âmbito do Sistema Único de Saúde.In: Brasil. Ministério da Saúde. Brasília; 2011.

11. Santos JAT, Oliveira MLF. Políticas públicas sobre álcool e outras drogas: breve resgate histórico. Saúde \& Transformação Social. 2013; 4, 82-89.

12. Silveira C,Doneda D, Gandolfi D, HoffmannMC, Macedo P, Delgado PG, et al.Política do Ministério da Saúde para atenção integral a usuários de álcool e outras drogas. Jornal Brasileiro de Psiquiatria. 2003;52; 349-354.

13. Brasil. Ministério da Saúde. Saúde Mental no SUS: Os Centros de Atenção Psicossocial. Brasília (DF); 2004.

14. Nasi C, Schneider JF. O Centro de Atenção Psicossocial no cotidiano dos seus usuários. Rev Esc Enferm USP. 2011; 45(5):1157-63.

15. Silva LO. Mulher, drogas e questões de gênero: Uma revisão da literatura [monografia]. Distrito Federal: Instituto de Psicologia, Unb; 2015.

16.Zanello V. Loucura e mulheres: questões de gênero para a psicologia clínica. In: Zanello, Valeska; Stevens, Cristina; Almeida, Tãnia; Brasil, 
Kátia. (Org). Gênero e feminismos: convergências (in) disciplinares. Brasilia: ExLibris, 2010, v., p. 307-320.

17. Souza MRR, Oliveira JF, Nascimento ER. A saúde de mulheres e o fenômeno das drogas em revistas brasileiras. Texto Contexto Enferm. 2014; 23(1): 92-100.

18. Fejes MAN, Ferigato SH, Marcolino TQ. Saúde e cotidiano de mulheres em uso abusivo de álcool e outras drogas. Rev Ter OcupUniv São Paulo. 2016;27(3):254-62.

19. Fertig A, Schneider JF, Oliveira GC, Olschowsky A, Camatta MW, Pinho LB. Mulheres usuárias de crack: Conhecendo suas histórias de vida. Esc Anna Nery. 2016;20(2):310-316.

20. Nicholson L. Interpretando o gênero. Revistas de Estudos Feministas. 2000; 8(2):8-41.

21. Zanello V, Fiuza HG, Costa HS. Saúde mental e gênero: facetas gendradas do sofrimento psíquico. Fractal, Rev. Psicol. 2015; 27(3):238246.

22. Zanello V, Silva RMS. Saúde Mental, gênero e violêncial estrutural. Revista Bioética. 2012; 20 (2): 267-279.

23. Hochgraf PB, Andrade AG. A questão dos gêneros nas farmacodependências. In: Cordas, TA; Salzano FT. Saúde Mental da Mulher. São Paulo: Editora Atheneu, p. 85-103. 2004.

24. Gimenez LBH. O estresse precoce como um dos determinantes do uso abusivo de substâncias psicoativas: revisão integrativa [dissertação]. Ribeirão Preto: Escola de Enfermagem, Universidade de São Paulo USP Ribeirão; 2015.

25.Joanna Briggs Institute. Reviewer's manual: 2014 edition. Adelaide, Australia: JBI; 2014.

26. Menezes SSC, Corrêa CG, Silva RCG, Cruz DAML. Raciocínio clínico no ensino de graduação em enfermagem: revisão de escopo. Rev Escola Enfermagem USP. 2015; 49; 1037-1044.

27. Micah DJ, Godfrey CM, Khalil H, Mclnerney P, Parker D, Soares CB. Guidance for conducting systematic scoping reviews. Intern Journ of Evidence-Based Healthcare. 2015; 13: 141-146.

28. Levac D, Colquhoun H, O'Brien KK. Scoping studies: advancing the methodology. Implementation Science. 2010; 5: 60-69.

29. Scott Joan. Gender on the Politics History. New York: Columbia University Press, 1988 (p.28-50).

30. Scott JW. O enigma da igualdade. Estudos feministas. 2005; 13(1): 11 30.

31. Finfgeld-Connett D,Johnson ED. Substance Abuse Treatment for Women who are UnderCorrectional Supervision in the Community: A SystematicReview of Qualitative Findings. Issues Ment Health Nurs. 2011; 32(10): 640-648.

32. Goodman D. Improving Access to Maternity Care for Women withOpioid Use Disorders: Colocation of MidwiferyServices at an Addiction Treatment Program. J MidwiferyWomens Health 2015;60:706-712.

33. Marcellus L, MacKinnon K, Benoit C,Phillips R,Stengel C. Reenvisioning Success for ProgramsSupporting Pregnant Women WithProblematic Substance Use. Qualitative Health Research. 2015; 25(4) 500-512. 
34. Lev - Ran S, Strat YL,Imtiaz S, Rehm J,Le Foll B. GenderDifferences in PrevalenceofSubstance Use Disorders among Individuals with Life time Exposureto Substances: Results from a Large Representative Sample. The American Journal on Addictions. 2013; 22: 7-13.

35. Rosen D, Tolman RM, Warner LA. Low-Income Women's Use of Substance Abuse and Mental Health Services. Journal of Health Care for the Poor and Underserved. 2004; 15(2): 206-219.

36. Brolin M, Horgan C, Doonan M. Substance Abuse Treatment in the Commonwealth of Massachusetts: Gaps, Consequences and Solutions. In: Policy Brief: The Massachusetts Health Policy Forum; 2006, Março; Estados Unidos. Estados Unidos, p. 01-08.

37. Okpaku S, Macmaster SA, Dennie S, Tolliver D, Cooper RL, Rasch RFR. Preliminary Outcomes of a model Program ffor Increasing Treatment Acess for African American Women who Use Crack Cocaine and are at Risk for Contracting HIV. Journal of Evidencce-Based Social Work. 2010; 7: 41-57.

38. Ponce AN, Lawless MS, Rowe M. Homelessness, Behavioral Health DisordersandlntimatePartnerViolence: Barriersto Services for Women. Community Ment Health J. 2014; 50:831-840.

39. Roberts KT, Robinson KM, Topp R, Newman J, Smith F, Stewart C. Community Perceptions of Mental Health Needs inan Underserved Minority Neighborhood. Journal of Community Health Nursing. 2008; 25:203-217.

40. Salt RJ, Costantino ME, Dotson EL, Paper BM. "You Are Not Alone" Strategies for Addressing Mental Health and Health Promotion with a Refugee Women's Sewing Group. Mental Health Nursing J. 2017; 38(4):337-343.

41. Shannon K, Rusch M, Shoveller J, Alexson D, Gibson K, Tyndall MW. Mapping violence and policing as an environmental-structural barrier to health service and syringe availability among substance-using women in street-level sex work. International Journal of Drug Policy. 2008; 19: 140147.

42. Metsch LR, Pollack HA. Welfare Reform and Substance Abuse. Milbank Q. 2005 Mar; 83(1): 65-99.

43. Moraes M, Castro R, Petuco D, coordenadores. Gênero e drogas: Contribuições para uma atenção integral à saúde. Recife: Creative Commons; 2011.

44. Oliveira JF, Nascimento ER, Paiva MS. Especificidades de usuários (as) de drogas visando uma assistência baseada na heterogeneidade. Esc Anna Nery Rev Enferm. 2007; 11(4):694-698.

45. Oliveira JF. (In)visibilidade no consumo de drogas como problema de saúde num contexto assistencial: uma abordagem de gênero [tese]. Salvador: Instituto de Saúde Coletiva, Universidade Federal da Bahia; 2008.

46. Cruz VD, Oliveira MM, Coimbra VCC, Kantorski LP, Pinho LB, Oliveira JF. Vivências de mulheres que consomem crack. Rev Rene. 2014; 15(4): 639649.

47. Drummond, M. P. Elementos para uma análise do machismo. São Paulo: Perspectivas; 1980. 
48. Souza DO, Silva SEV, Silva NO. Determinantes sociais da saúde: reflexões a partir das raízes da "questão social". Saúde Soc. 2013; 22(1): 44-56.

49. Moreira CB, Fernandes AFC, Castro RCMB, Oliveira RDP, Pinheiro AKB. Levantamento de determinantes sociais de saúde relacionados à adesão ao exame mamográfico. Rev Bras Enferm. 2018;71(1):106-12.

50. Santos DS, Tenório EA, Brêda MZ, Mishima SM. Processo saúde/doença e estratégia de saúde da família: o olhar do usuário. Rev. Latino-Am. Enfermagem. 2014;22(6):918-925.

51. Organização Mundial da Saúde. Mulheres e Saúde: Evidências de Hoje Agenda de amanhã, 2017.

52. Buss PM, Pellegrini Filho A. A saúde e seus determinantes. Revista de Saúde Coletiva. 2007; 17(1): 77-93.

53. Whitehead $M$. The concepts and principles of equity and health. Copenhagen: World Health Organization. Regional Office for Europe, 2000.

54. Oliveira MJI, Espírito Santo E. A relação entre os determinantes sociais da saúde e a questão social. Caderno Saúde e Desenvolvimento. 2013; 2(2): 8-24.

55. Bard ND, Antunes B, Roos CM, Olschowsky A, Pinho LB. Estigma e preconceito: vivência dos usuários de crack. Rev. Latino-Am. Enfermagem. 2016; 24: 1-8.

56. Goffman, E. (1978). Estigma: notas sobre a manipulação da identidade deteriorada (2a ed.). Rio de Janeiro: Zahar

57. Silveira PS, Martins LF, Soares RG, Gomide HP, Ronzani TM. Revisão sistemática da literatura sobre estigma social e alcoolismo. Estudos de Psicologia. 2011; 16(2): 131-138.

58. I Levantamento Nacional sobre os Padrões de Consumo de Álcool na População Brasileira. Secretaria Nacional Antidrogas (Senad). Brasília; 2007.

59. Scheffer M, Almeida RMM. Consumo de álcool e diferenças entre homens e mulheres: comportamento impulsivo, aspectos cognitivos e neuroquimicos. Revista de Neuropsicologia Latinoamericana. 2010. 2(3): $1-11$.

60. Arksey H, O'Malley L. Scoping studies: towards a methodological framework. Journal International Journal of Social Research Methodology. 2005; 8(1): 19-32.

61. Nóbrega MPSS. Mulheres usuárias de Álcool e Drogas llícitas: Divergências e Convergências entre Dois Universos [tese]. São Paulo: Universidade Federal de São Paulo; 2007.

62. United Nations. Office on Drugs and Crime. Substance abuse treatment and care for women: Case studies and lessons learned [Internet]. Vienna; 2004. [Acesso 15 jan 2019]. Disponível em: https://www.unodc.org/pdf/report 2004-08-30 1.pdf

63. Villa EA, Pereira MO, Reinaldo AMS, Neves NAP, Viana SMN. Perfil Sóciodemográfico de mulheres em Situação de Rua e a Vulnerabilidade para o Uso de Substâncias Psicoativas. Rev enferm UFPE online. 2017; 11(5):2122-31. 
64. Orsine AOLM, Silva KL, Jorge AO, Pereira MO. Sofia: Narrativa de uma História de Abandono e Sequestro dos Direitos de Vir a Ser. Saúde em Redes. 2018; 4(1): 75-83. 


\section{Apêndices}

1.1. Formulário de Extração de Dados - Apêndice 1

\begin{tabular}{|l|}
\hline \multicolumn{1}{|c|}{ Formulário de Extração de Dados } \\
\hline Autor (es) do estudo: \\
\hline Ano de publicação do estudo: \\
\hline País de origem da publicação: \\
\hline População Alvo: \\
\hline Objetivos/Finalidade do estudo: \\
\hline Tamanho da amostra (se aplicável): \\
\hline Metodologia: \\
\hline Conceito: \\
\hline Resultados: \\
\hline Achados cabíveis a presente revisão: \\
\hline
\end{tabular}




\title{
1.2. Protocolo da Revisão de Escopo - Apêndice 2
}

\section{O acesso das mulheres a serviços comunitários de saúde mental em álcool e outras drogas: um protocolo de uma análise de escopo}

\author{
Thais Yshida Cestari Lockley ${ }^{1}$ \\ Márcia Aparecida Ferreira de Oliveira ${ }^{1}$
}

1. Universidade de São Paulo

Autor correspondente:

Thais Yshida Cestari Lockley

thaisyshida@gmail.com

\section{Objetivo}

O objetivo dessa revisão é examinar e mapear a área de conhecimento acerca do acesso das mulheres em serviços comunitários de saúde mental álcool e outras drogas.

\section{Introdução}

A questão do uso de álcool e outras drogas é uma problemática de saúde pública enfrentada por muitas pessoas e profissionais. Com relação a diferença de gênero, nota-se que os padrões de consumo de álcool, tabaco e outras drogas das mulheres têm se aproximado dos padrões dos homens ${ }^{(1)}$.

Estudos epidemiológicos nacionais (2) demonstram um crescente aumento de mulheres dependentes de álcool e outras drogas, considerando alta prevalência de problemas relacionados ao consumo nesse recorte de gênero ${ }^{(1-}$ 3).

Mudanças políticas e culturais ocorridas no final do século XX trouxeram para tal população maior inserção no mercado de trabalho e logo, aumento do número de famílias chefiadas por mulheres. Neste sentido, as mulheres passaram a estar expostas aos mesmos riscos sociais (consumo de substâncias psicoativas) nos quais os homens estavam (1).

Esse fato vai de encontro com a problemática aqui proposta a estudar. Mulheres consumindo mais substâncias psicoativas permeia a complexidade de tal fenômeno - relações sociais e meio no qual estão inseridas. Podemos pensar 
e refletir acerca do papel da mulher na sociedade que possa estar the causando sofrimento psíquico a tal população ${ }^{(1)}$.

Vale ressaltar que a imagem e o papel das mulheres na sociedade contemporânea não estão associados ao estereótipo de usuárias de álcool e outras drogas. E essa circunstância contribuiria para a invisibilidade das mulheres nesse contexto, aumento os agravos em sua saúde (1).

Estudos realizados em CAPS no Brasil, com enfoque do gênero feminino retratam um pouco da caracterização das mulheres que fazem uso/uso abusivo de álcool e outras drogas. Um ponto de destaque importante a ser analisado e refletido é com relação ao início precoce de uso - a influência familiar acerca do consumo de álcool (4).

No mesmo estudo, outro fator no qual foi dado importância é aos sentimentos gerados no passado e no presente com relação ao consumo da droga. Brigas, desavenças e violências familiares são propiciadores ao uso da substância psicoativa. Após o incio do consumo de álcool e outras drogas perda dos laços de afetividade/familiares e fragilidades no relacionamento interpessoal são destacados ${ }^{(4)}$.

Serviços comunitários em saúde mental e política de álcool e outras drogas devem estar preparados para acolher a demanda das mulheres priorizando as necessidades singulares de gênero como: estigma social derivado de uma cultura sexista no qual estão inseridas, dificuldades ao buscar tratamento (filhos, casamento), maior frequência de riscos sexuais, entre outros ${ }^{(4)}$.

Frente a isso, um estudo contribuiu para que as práticas em saúde devem ser substituídas por ações que alcancem o cuidado psicossocial, comprometido com as demandas psíquicas e sociais das mulheres, refletindo e corroborando com as diferenças de gênero aqui apontadas (5).

Assim faz-se importância o conhecimento da inserção das mulheres na sociedade, enquanto sujeito; a compreensão das relações sociais que as mesmas estabelecem e das desigualdades de gênero que permeiam as relações e que são enfrentadas a fim de auxiliar a compreensão do fenômeno das drogas (1-4).

O cuidado em Saúde Mental deve ser de forma integral e singular; conhecer a trajetória das mulheres permite identificar os significados expressos 
pelas mesmas a fim de contribuir para o planejamento do processo terapêutico (1-4-5).

\section{Pergunta de Revisão}

Assim, pergunta-se quais barreiras influenciam o acesso das mulheres em serviços comunitários de saúde mental em álcool e outras drogas?

\section{Palavras-chave}

Português: Serviços Comunitários de Saúde Mental; Mulher(es); Transtornos Relacionados ao Uso de Substâncias; Enfermagem.

Inglês: Community Mental Health Services; Women; Disorders Related to Substance Use; Nursing.

Espanhol: Servicios Comunitários de Salud Mental; Mujer (es); Transtornos Relacionados com el Uso de Substancias; Enfermería.

\section{Critério de inclusão}

\section{Tipos de participantes}

A revisão considerará estudos que incluem as mulheres usuárias de álcool e outras drogas.

\section{Conceito}

Acesso aos serviços de saúde mental em álcool e outras drogas.

\section{Contexto}

Os estudos deverão estar dentro do contexto da Atenção Integral às mulheres usuárias de álcool e outras drogas.

\section{Tipos de fontes}

Esta revisão de escopo considerará modelos de estudos experimentais e quase experimentais, incluindo ensaios controlados randomizados e ensaios controlados não randomizados ${ }^{(6)}$.

Além disso, estudos analíticos de observação, estudos de coorte prospectivos e retrospectivos, estudos de casos-controle e estudos analíticos 
transversais também serão avaliados para inclusão. Esta revisão também considerará projetos descritivos de estudo observacional, incluindo séries de casos, relatos de casos individuais e estudos descritivos transversais para inclusão (6).

Por fim, serão avaliados para inclusão, documentos governamentais, Estudos primários qualitativos, quantitativos, econômicos e de métodos mistos; bem como revisões sistemáticas e revisões de revisões (6) relacionadas às barreiras que influenciam o acesso de mulheres em serviços comunitários de saúde mental em álcool e outras drogas, que atendam aos critérios de inclusão.

\section{Estratégia de pesquisa}

A estratégia de busca tem como objetivo identificar estudos publicados e não publicados. Inicialmente será realizado um levantamento bibliográfico nas seguintes bases de dados: Biblioteca Virtual em Saúde (BVS), US National Library of Medicine National Institutes of Health (Pubmed), Web of Science, Sci Verse Scopus (Scopus), American Psychological Association (Psyinfo), Cumulative Index to Nursing and Allied Health Literature (Cinahal), Index Psy Periódicos (indexpsy) e EMBASE.

Os Estudos publicados em português, inglês, espanhol serão considerados como potencialmente elegíveis para inclusão nesta revisão.

Os artigos identificados serão analisados de acordo com a relevância, por meio das informações do título e resumo, por dois revisores independentes. $O$ artigo completo será recuperado para estudos que parecerem compreendidos frente aos critérios de inclusão da revisão. Se os revisores tiverem incertezas sobre a relevância de um estudo a partir do título e resumo, o artigo completo será recuperadopara análise.

Após análise integral dos estudos potencialmente elegíveis, dois avaliadores selecionarão os estudos, de forma independente em conformidade com oscritérios de inclusão e do objetivo. Serão excluídos da presente revisão os estudos repetidos em diferentes bases de dados.

\section{Extração dos dados}

Os dados serão extraídos dos estudos incluídos na revisão por dois revisores independentes por meio do formulário de extração de dados orientado 
pelos objetivos da revisão. O formulário de extração de dados foi desenvolvido especificamente para esta revisão de escopo (Anexo I), no qual permitirá a extração dos dados relevantes de cada documento ${ }^{(6)}$.

As modificações serão detalhadas no relatório completo de análise de escopo. Caso for necessário, os autores dos trabalhos serão contatados para solicitar dados em falta ou adicionais.

\section{Apresentação dos resultados}

Os resultados incluídos na presente revisão de escopo serão classificados em categorias de análise conceituais e discorridos em meio ao referencial teórico.

O referencial teórico que permeará o embasamento será de Joan Wallach Scott. Uma historiadora norte-americana que iniciou os estudos na trajetória das mulheres em 1980.

\section{Conflitos de interesse}

Declaro que não há conflitos de interesse.

\section{Referências}

1. Silva LO. Mulher, drogas e questões de gênerp: Uma revisão da literatura [monografia]. Distrito Federal: Instituto de Psicologia, Unb; 2015.

2. Carlini EA, Galduróz JCF, Noto AR, Fonseca AM, Carlini CM, Oliveira LG, Nappo AS, Moura YG, Sanchez ZVDM. II Levantamento Domiciliar sobre o Uso de Drogas Psicotrópicas no Brasil: estudo envolvendo as 108 maiores cidades do país - 2005. São Paulo: Centro Brasileiro de Informações sobre Drogas Psicotrópicas (CEBRID); Universidade Federal de São Paulo; 2005.

3. Zanello V. Loucura e mulheres: questões de gênero para a psicologia clínica. In: Zanello, Valeska; Stevens, Cristina; Almeida, Tãnia; Brasil, Kátia. (Org). Gênero e feminismos: convergências (in) disciplinares. Brasilia: ExLibris, 2010, v., p. 307-320.

4. Fejes MAN, Ferigato SH, Marcolino TQ. Saúde e cotidiano de mulheres em uso abusivo de álcool e outras drogas. Rev Ter OcupUniv São Paulo. 2016;27(3):254-62.

5. Fertig A, Schneider JF, Oliveira GC, Olschowsky A, Camatta MW, Pinho LB. Mulheres usuárias de crack: Conhecendo suas histórias de vida. Esc Anna Nery. 2016;20(2):310-316.

6. Joanna Briggs Institute. Reviewer's manual: 2014 edition. Adelaide, Australia: $\mathrm{JBI} ; 2014$. 